\title{
Self-Assembled Complexes of Non-cross-linked Amphiphilic Polymeric Ligands with Inorganic Species: Highly Active and Reusable Solid-Phase Polymeric Catalysts
}

\author{
Yoichi M. A. YAMADA \\ Institute for Molecular Science; Myodaiji, Okazaki, Aichi 444-8787, Japan. \\ Received March 16, 2005
}

\begin{abstract}
I present herein the development of highly active and reusable polymeric catalysts produced by self-assembly process of non-cross-linked amphiphilic polymeric ligands with inorganic species. Thus, PWAA 1 prepared from $\mathrm{H}_{3} \mathrm{PW}_{12} \mathrm{O}_{40}$ and poly[( $N$-isopropylacrylamide)-co-(acrylamide with ammonium salt)] is suitable for oxidation of alcohols, amines, and sulfides in aqueous hydrogen peroxide. PdAS 2 produced by self-organization of $\left(\mathrm{NH}_{4}\right)_{2} \mathrm{PdCl}_{4}$ and poly[ $(\mathrm{N} \text {-isopropylacrylamide })_{10}$-co-diphenylphosphinostyrene] is an excellent recyclable catalyst for Suzuki-Miyaura reaction in water, water-organic solvent, and organic solvent. It is commercially available from Tokyo Kasei Kogyo (TCI). PdAS-V 3 assembled from $\left(\mathrm{NH}_{4}\right)_{2} \mathrm{PdCl}_{4}$ and poly[ $(N \text {-isopropylacrylamide })_{5}$-codiphenylphosphinostyrene] provides recycling system of itself for Mizorogi-Heck reaction. TiSS 4 made from $\mathrm{Ti}(\mathrm{O}-i \text {-Pr })_{4}$ and poly(styryl-linked binaphtholate-co-styrene) promotes an enantioselective carbonyl-ene reaction as a recyclable catalyst.
\end{abstract}

Key words immobilized polymeric catalyst; reusable solid-phase catalyst; self-assembly; tungsten; palladium; titanium

\section{Introduction}

Development of immobilized and insoluble metal catalysts is of great interest in recent organic chemistry. ${ }^{1-9)}$ The simple recovery of catalysts by filtration and their reuses resulted in enhancing the economical evaluation of the reaction. At the same time, there is a prospect that the environmental pollution caused by residual metals in the waste fluid will be decreased. Although a great deal of effort has been made to carry out such ideal reactions using immobilized metal catalysts, what seems to be lacking is the efficiency of the catalytic systems. It is obvious that the heterogeneous catalytic systems exhibit generally lower activity than the homogeneous ones. Besides, it is expected that the activity of the catalysts decreases gradually in the recycled systems because the metal species leaches away from their supports. Taking these into consideration, we decided to concentrate on developing insoluble metal catalysts which are highly active and stable. We designed that they were still effective in the use of ppm mol eq, and in the recycled use of many times in any reaction media. To achieve the challenging theme, we have focused on the amphiphilic insoluble catalysts based on a novel concept (Chart 1).

Over the past few decades, a considerable numbers of study have been made on solid-phase catalysts which were immobilized with cross-linked polystyrene resins, silica gels or metals. These catalytic systems, however, generally resulted in lower catalytic activity compared with their soluble counterparts, and were often obliged to use hazardous chlorohydrocarbon solvents. ${ }^{10-15)}$ Besides, reuse of these catalysts was often difficult owing to the gradual decline of the catalytic activity. These problems made them less practical.

In traditional triphase catalysts, as I have mentioned before, a catalytic species was anchored to a linker that was immobilized to a polymer resin or silica gel (Chart 1, above). In

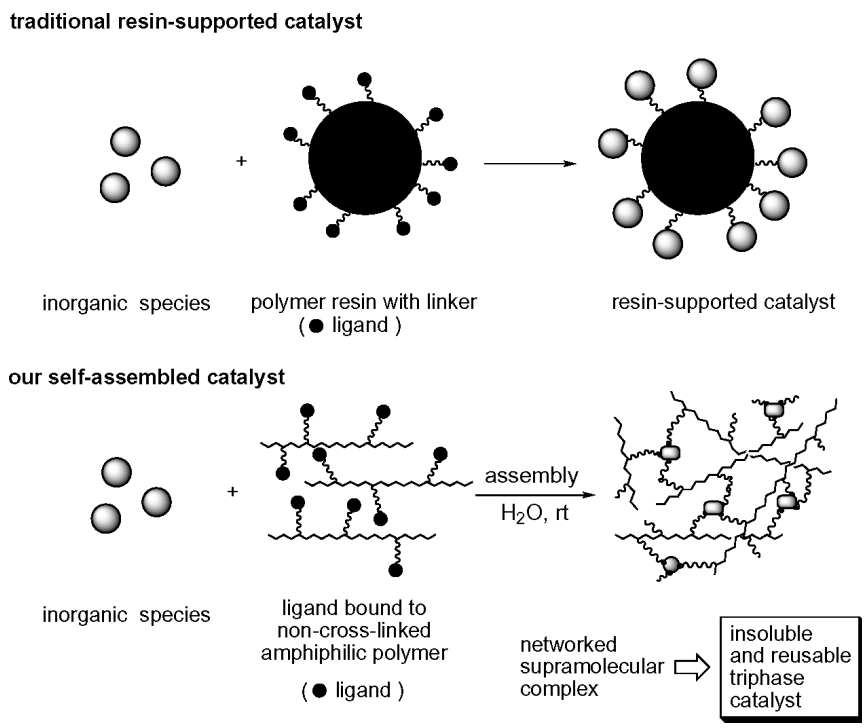

Chart 1. Hypothesis of Formation of a Self-Assembled Complex for an Insoluble Ooxidation Catalyst 
our approach, however, the insoluble catalysts were constructed from self-assembly process of non-cross-linked amphiphilic copolymer ligands and inorganic species. This process would promote the cross-linking of the copolymer by the inorganic species to provide networked, supramolecular, and insoluble complexes (Chart 1 , below). They might possess many mesopores where the inorganic species would be tightly supported by many ligands not to be dissociated. We expected such complexes should act as highly active catalysts based on the following points: 1) the complexes have a characteristic high-to-volume ratio to react with a substrate and a reagent, 2) they can capture these reagents effectively by their mesopores, and 3) the amphiphilic copolymers and the inorganic species might construct effective catalytic sites with high affinity to both hydrophobic and hydrophilic reagents.

In this review, I describe the development of self-assembled catalysts PWAA (poly $\left\{\underline{\mathrm{PW}}_{12} \mathrm{O}_{40}{ }^{3-}[(N\right.$-isopropylacrylamide)-co-(acrylamide with ammonium salt) $\left.\left.]_{3}\right\}\right)$ (1), $\mathrm{PdAS}$ (poly $\left\{\mathrm{PdCl}_{2}\left[(N \text {-isopropylacrylamide })_{10}\right.\right.$-co-diphenylphosphinostyrene $\left.]_{2}\right\}$ ) (2), PdAS-V (poly $\left\{\underline{\mathrm{PdCl}}_{2}[(N\right.$-isopropylacrylamide $)_{5}$-co-diphenylphosphinostyrene $\left.\left.]_{2}\right\}\right)$ (3), and TiSS (poly( $\underline{T} \underline{i}$ styryl-linked binaphtholate-co-styrene)) (4) prepared from metal ions and non-cross-linked amphiphilic (except 4) polymers, and their application to the heterogeneous organic synthetic reactions. These catalysts showed outstanding stability in any reaction media such as water, aqueous or anhydrous organic solvents and was reused as follows. ${ }^{16-23)}$

\section{Development of a Novel Solid-Phase Tungsten Cata- lyst PWAA and Its Application to Oxidation}

2.1. Preparation of a Triphase Catalyst PWAA PWAA 1 was prepared as shown in Chart 2. Ammonium salt 7 was synthesized from commercially available $N$-[3-(dimethylamino)propyl]acrylamide with 1-bromododecane in $92 \%$ yield. Random copolymerization of 5 with $12 \mathrm{~mol}$ eq of $\mathbf{6}$ were performed in the presence of $0.04 \mathrm{~mol}$ eq of AIBN in $t$ $\mathrm{BuOH}$ at $75^{\circ} \mathrm{C}$ for $48 \mathrm{~h}$, resulting in that non-cross-linked polymer 7-Br was formed. It was an amphiphilic polymer that was soluble in water, $t-\mathrm{BuOH}$, and $\mathrm{CH}_{2} \mathrm{Cl}_{2}$. The ratio of the $\mathrm{N}$-isopropylacryl amide unit to the ammonium unit to be 12/1 was determined by ${ }^{1} \mathrm{H}-\mathrm{NMR}$. The bromide 7-Br was ion-exchanged to the nitrate $\mathbf{7}-\mathrm{NO}_{3} \cdot{ }^{24)}$ The molecular weight of 7-NO $\mathrm{NO}_{3}$ was wide-ranging (thousands to tens of thousands) as a result of gel-permeation chromatography relative to polystyrene standards. Thus, complexation to form PWAA was carried out according to the procedure for the preparation of $\left[\pi-\mathrm{C}_{5} \mathrm{H}_{5} \mathrm{~N}\left(\mathrm{CH}_{2}\right)_{15} \mathrm{CH}_{3}\right]_{3} \mathrm{PW}_{12} \mathrm{O}_{40} \cdot{ }^{25)}$ A self-assembly process of $\mathbf{8}$ with $\mathbf{7 - \mathbf { N O } _ { 3 }}$ (3 mol eq of an ammonium unit) in water at room temperature resulted in the formation of white insoluble precipitates simultaneously. After stirring for $7 \mathrm{~d}$ at the same temperature, the resulted precipitate was washed and dried to give PWAA as white lumps. PWAA were insoluble in $\mathrm{H}_{2} \mathrm{O}$ and organic solvents such as $\mathrm{MeOH}$, EtOH, $i$ $\mathrm{PrOH}, \mathrm{AcOEt}, \mathrm{Me}_{2} \mathrm{CO}, \mathrm{CH}_{2} \mathrm{Cl}_{2}$, toluene, $\mathrm{Et}_{2} \mathrm{O}$ and hexane. Addition of $\mathbf{8}$ to poly( $N$-isopropylacrylamide) afforded no precipitates. This result indicated that the existence of the ammonium salt units in 7 was essential for cross-linking the polymers through phosphotungstates.
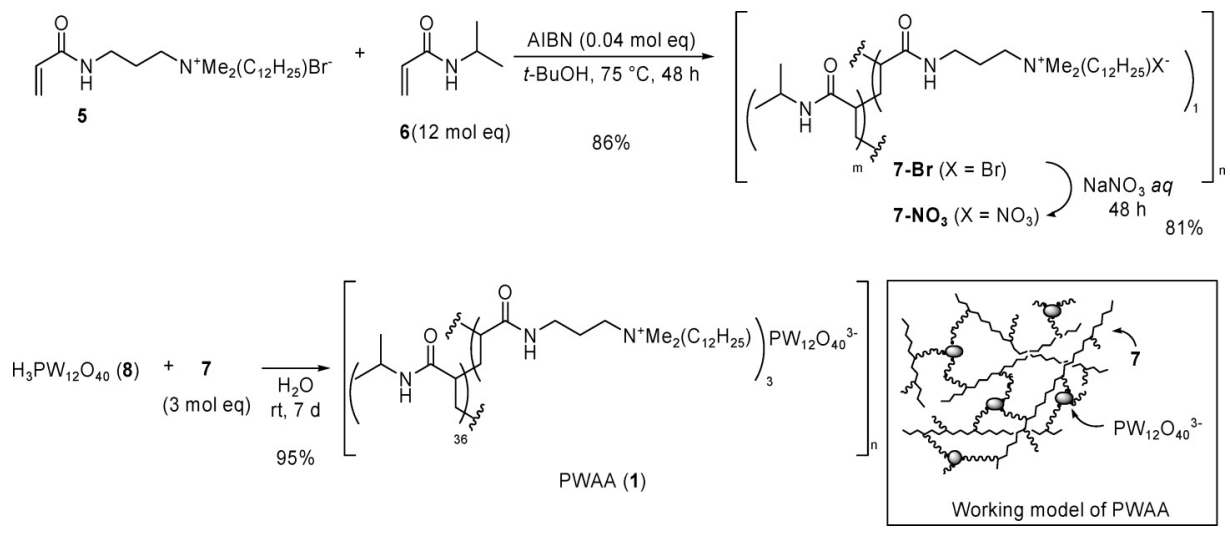

Chart 2. Preparation of PWAA 1

Yoichi M. A. Yamada was born in 1970 in Tokyo, Japan. He received his bachelor's degree from the University of Tokyo in 1994 under the direction of Professor Masakatsu Shibasaki, and awarded his Ph. D. degree from the University of Tokyo in 1999 under the supervision of Professor Masakatsu Shibasaki. In 1999-2003, he had joined the group of Professor Shiro Ikegami (ex-chairperson of Pharmaceutical Society of Japan) in Teikyo University as an assistant professor, and he moved to Prof. K. C. Nicolaou's group in Scripps Research Institute as a research associate (2003-2004). After returning to Japan, he joined Prof. Yasuhiro Uozumi's group in Institute for Molecular Science as an assistant professor. He has received the Dainippon Ink and Chemicals Award in Synthetic Organic Chemistry (1999), the Inoue Research Award for Young Scientists (2000), and the Pharmaceutical Society Award for Young Scientists (2005).

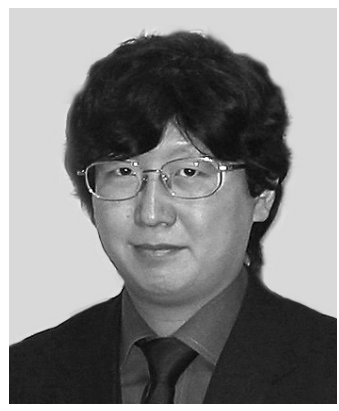

Yoichi M. A. Yamada 
To elucidate the structure of PWAA, several spectroscopic measurements were examined. The elementary analysis showed that one complex unit of $\mathbf{1} \cdot 22 \mathrm{H}_{2} \mathrm{O}$. The infrared spectrum of PWAA exhibited strong vibrations at 1080 $(\mathrm{P}=\mathrm{O}), 978(\mathrm{~W}=\mathrm{O}), 897$ and $818 \mathrm{~cm}^{-1}$, while that of 8 exhibited them at 1080, 982, 893 and $808 \mathrm{~cm}^{-1}$. Viewed in this light, the structure of the phosphotungstic acid unit of PWAA can be regarded as that of $\mathbf{8}$.

Furthermore, we analyzed PWAA by gel-phase ${ }^{31} \mathrm{P}-\mathrm{NMR}$; a broad singlet peak was detected at $-13 \mathrm{ppm}$ (Fig. 1). Since it was reported that the signals of $\mathrm{H}_{3} \mathrm{PW}_{12} \mathrm{O}_{40}$ and $[\pi$ $\left.\mathrm{C}_{5} \mathrm{H}_{5} \mathrm{~N}\left(\mathrm{CH}_{2}\right)_{15} \mathrm{CH}_{3}\right]_{3} \mathrm{PW}_{12} \mathrm{O}_{40}$ were observed at the similar frequency $\left(-14.7 \mathrm{ppm}^{26)}\right.$ and $-14.5 \mathrm{ppm}^{27)}$ respectively), it would be supported that phosphotungstate in PWAA maintained the heteropoly acidic structure such as the Keggin type $\left(\mathrm{PW}_{12} \mathrm{O}_{40}^{3-}\right) \cdot{ }^{28,29)}$

A scanning electron microscope (SEM) of PWAA was also investigated (Fig. 2). PWAA was treated with gold vapor by the sputter-coating method. It was observed that PWAA possessed many pores, whose diameter was about $1-10 \mu \mathrm{m}$ (left) and hundreds nanometer or less (center). Further magnification $(\times 50000)$ showed many projections those lengths were less than $100 \mathrm{~nm}$ (right); All these things make it clear

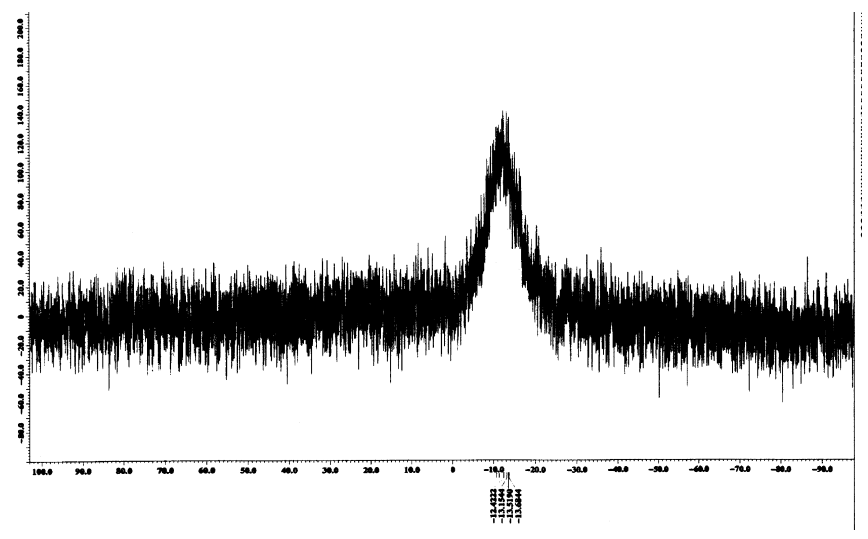

Fig. 1. A Gel-Phase ${ }^{31}$ P-NMR Chart of PWAA that PWAA has a high surface-to-volume ratio and many reactive sites.

2.2. Epoxidation of Allylic Alcohols Catalyzed by PWAA With the insoluble complex PWAA in hand, the epoxidation of allylic alcohols with aq. $\mathrm{H}_{2} \mathrm{O}_{2}$ under the organic solvent-free conditions was examined. ${ }^{30-42)}$ We were pleased to find that PWAA showed a very high catalytic activity on epoxidation. In the presence of $2.7 \times 10^{-5} \mathrm{~mol} \mathrm{eq}$ of PWAA, the reaction of phytol (9a) with 2 mol eq of $30 \%$ aq. $\mathrm{H}_{2} \mathrm{O}_{2}$ resulted in the corresponding epoxy alcohol 10a in 94\% yield (Chart 3). TON of PWAA was approximately 35000. This result showed that PWAA has a superior catalytic activity compared with the precedent.

Since the catalytic activity of PWAA was evaluated, a series of epoxidation of several allylic alcohols was performed in the presence of $5.0 \times 10^{-4} \mathrm{~mol}$ eq of PWAA (Table 1). Hydrophobic substrates of 9a and farnesol (9b) were converted to the corresponding epoxides in high yields. Epoxidation of 9a proceeded in $7 \mathrm{~h}$ at room temperature to give 10a in $96 \%$ yield with TON reaching approximately 2000 (entry 1). In
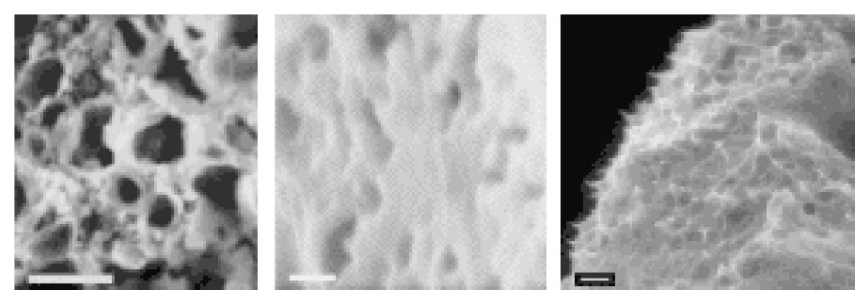

Fig. 2. Scanning Electron Micrographs (SEM) of PWAA

Left: scale bar, $10 \mu \mathrm{m}$; center: scale bar, $500 \mathrm{~nm}$, right; scale bar: $100 \mathrm{~nm}$.

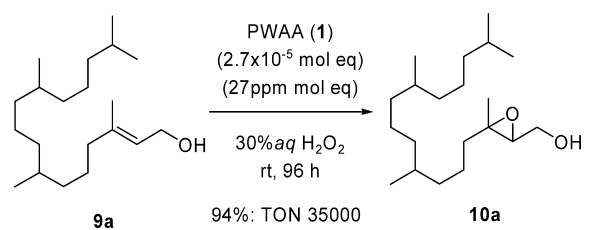

Chart 3. Epoxidation of Phytol (9a) Promoted by PWAA

Table 1. Epoxidation of Allylic Alcohols Promoted by PWAA

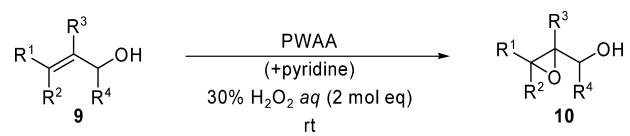

\begin{tabular}{|c|c|c|c|c|c|c|}
\hline Entry & Substrate & & PWAA 1 (mol eq) & Pyridine (mol eq) & Time $(\mathrm{h})$ & Yield $(\%)^{a)}$ \\
\hline 1 & & $9 a$ & $5.0 \times 10^{-4}$ & - & 7 & 10a: 96 \\
\hline 2 & & $9 b$ & $5.0 \times 10^{-4}$ & - & 13 & 10b: 84 \\
\hline 3 & & $9 c$ & $5.0 \times 10^{-4}$ & $6.0 \times 10^{-3}$ & 15 & 10c: 80 \\
\hline 4 & & 9d & $5.0 \times 10^{-4}$ & $6.0 \times 10^{-3}$ & 12 & 10d: 83 \\
\hline 5 & & $9 e$ & $5.0 \times 10^{-4}$ & $6.0 \times 10^{-3}$ & 13 & 10e: 96 \\
\hline 6 & & 9f & $2.0 \times 10^{-3}$ & $9.6 \times 10^{-2}$ & 30 & 10f: quant \\
\hline 7 & & $9 g$ & $2.0 \times 10^{-3}$ & $2.4 \times 10^{-2}$ & 33 & 10g: quant \\
\hline 8 & & $9 h$ & $2.0 \times 10^{-3}$ & $9.6 \times 10^{-2}$ & 85 & $\begin{array}{c}\text { 10h: } 73 \\
(\text { threo }: \text { erythro }=91: 9)\end{array}$ \\
\hline
\end{tabular}


the reaction of $\mathbf{9 b}, 2,3$-epoxy alcohol $\mathbf{1 0 b}$ was obtained in $84 \%$ yield (entry 2). In this case, other trialkylsubstituted alkene moieties were intact. Although the epoxidation of less hydrophobic geraniol (9c) was messy to afford 10c in $12 \%$ yield owing to acidic hydrolysis of the epoxide, we found that the addition of a trace amount of pyridine was effective to reduce an acidity in this system and thus to prevent the epoxide-opening reactions (entry 3). ${ }^{43}$ ) The reaction of $9 \mathbf{c}$ in the presence of PWAA and $6.0 \times 10^{-3} \mathrm{moleq}$ of pyridine for $15 \mathrm{~h}$ resulted in the formation of $10 \mathrm{c}$ in $80 \%$ yield (entry 4 ), where the $\mathrm{C}(6)-(7)$ double bond was not affected. Under identical conditions, trisubstituted allylic alcohols such as an exocyclic allylic alcohol 9d and a linear one 9e provided the corresponding epoxides in high yields (entries 4, 5). Although disubstituted allylic alcohols were less reactive, they were converted to the corresponding epoxides in quantitative yields by using $2.0 \times 10^{-3}$ mol eq of PWAA (entries 6,7 ). Besides, the diasteroselective epoxidation of 2-methyl-2-octen4-ol (9h) furnished the threo-selective epoxy alcohol $\mathbf{1 0 h}$ in $73 \%$ yield (threo/erythro $(91: 9)$ ) (entry 8 ).

The proximity effect of allylic alcohol was also investigated (Chart 4). Epoxidation of a phytol-methyl ether, a phytol-acetyl ester and a phytol-pivaloyl ester under identical conditions did not proceed at all. Besides, the mixture of phytol (9a) and cyclohexene resulted in the quantitative conversion of phytol and the no reaction of cyclohexene under the identical conditions (Chart 5). Considered these results, epoxidation was promoted by the interaction of hydroxyl group of allylic alcohol with PWAA which is similar to early transition metal catalyses. ${ }^{44)}$

Moreover, recycling of PWAA in case of 9a was examined as shown in Chart 6. It was found that PWAA was reused three times; in the 1 st to 3 rd cycle runs, the product 10a was given in 96, 93, and $97 \%$ yields respectively. The activity of PWAA was unchanged under the oxidation conditions through the consecutive runs although PWAA was pulverized through runs.

2.3. Oxidation of Amines Catalyzed by PWAA Since PWAA efficiently promoted the epoxidation of allylic alcohols, we applied this oxidation system to secondary amines. ${ }^{45-56)}$ Oxidation of secondary amines is the most straightforward method and the direct route to prepare nitrones, which are important substrates for the synthesis of nitrogen-containing bioactive compounds. It was beforehand confirmed that no oxidation of dibenzylamine (11a) with hydrogen peroxide was observed at room temperature. On the contrary, addition of $2 \times 10^{-3}$ mol eq of PWAA to this reaction system promoted oxidation to give the corresponding nitrone (12a) in $86 \%$ yield (Table 2, entry 1$).{ }^{57)} \mathrm{Bis}(p$-substituted benzyl)amines were also converted to the corresponding oximes under similar conditions. The reaction of bis[(4trifluoromethyl)benzyl]amine (11b) proceeded smoothly to afford $\mathbf{1 2 b}$ in $90 \%$ yield. TON of PWAA in this oxidation reached 450. However, bis(4-chlorobenzyl)amine (11c) and bis(4-methoxybenzyl)amine (11d) were converted to 12c and d in moderate yields. We further examined the regioselective oxidations of bis( $p$-substituted benzyl)amines. Although it seemed reasonable that the deprotonation took place at more acidic benzylic position selectively, the reactions gave nitrones in $71-94 \%$ yield albeit with low regioselectivity $(1.3 / 1-1.7 / 1)($ entries $5-7){ }^{58)}$ Turning to cyclic secondary

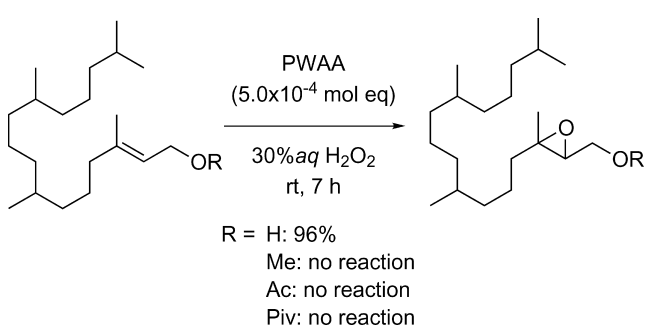

Chart 4. The Epoxidation of Phytol Derivatives

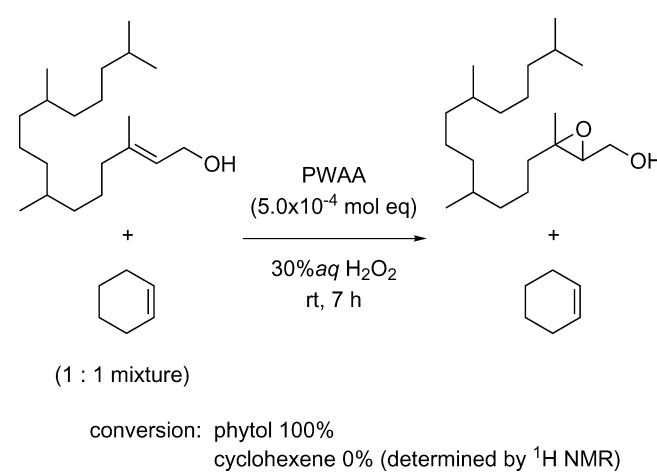

Chart 5. Epoxidation of the Mixture of Phytol and Cyclohexene Promoted by PWAA

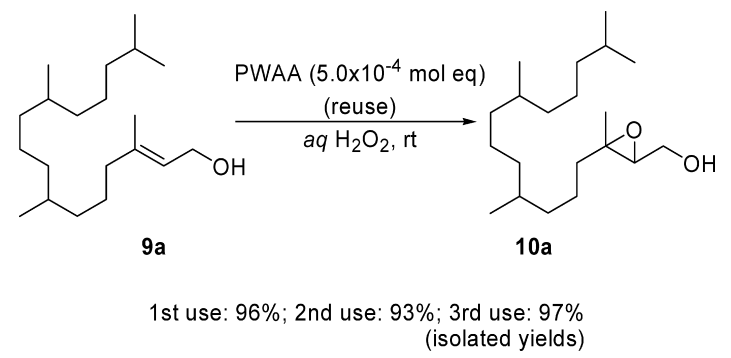

Chart 6. Epoxidation of Phytol (9a) Catalyzed by Recycled PWAA

amines, tetrahydroisoquinoline (11i) was converted to $\mathbf{1 2} \mathbf{i}$, which is the useful substrate for the synthesis of isoquinoline alkaloids, in 70\% yield (entry 9). Oxidation of tetrahydroquinoline $(\mathbf{1 1} \mathbf{j})$ provided $\mathbf{1 2} \mathbf{j}$ instead of the corresponding nitrone (entry 10).

2.4. Oxidation of Sulfides Catalyzed by PWAA Next, we turned our attention to oxidation of sulfides to sulfones (Table 3). ${ }^{59-67)}$ Sulfones have been utilized as the syntons for total synthesis of bioactive natural compounds. As depicted in parenthesis in Table 3, oxidation of $13 \mathbf{a}-\mathbf{k}$ with hydrogen peroxide in the absence of PWAA proceeded sluggishly to give mainly the corresponding sulfoxides $14 \mathbf{a}-\mathbf{k}$ in low to moderate yields ${ }^{68)}$ rather than sulfones $15 \mathbf{a}-\mathbf{k}$. Meeting our expectations, PWAA efficiently promoted the oxidation of sulfides to give sulfones under similar conditions. In the presence of $2 \times 10^{-3}$ mol eq of PWAA, 13a was converted into 15a in $97 \%$ yield (entry 1 ). TON of PWAA reached approximately 500 . The substituted aryl methyl sulfides were also converted to the corresponding sulfones in high yields $(84-90 \%)$ (entries 3, 5, 7). Similarly, oxidation of alkyl thiophenols also provided the corresponding sulfones in high yields (entries 9, 15, 17, 19). It is notable that the catalytic system tolerates a wide variety of functional group. For example, methylthio benzothiazole (13f) that is a useful nucle- 
Table 2. Oxidation of Secondary Amines by PWAA

\begin{tabular}{|c|c|c|c|c|c|c|c|}
\hline \multirow[b]{2}{*}{ Entry } & \multirow[b]{2}{*}{ Amines } & \multirow[b]{2}{*}{$\mathrm{R}^{1}$} & \multicolumn{2}{|c|}{ 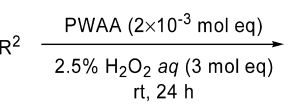 } & \multicolumn{2}{|c|}{ 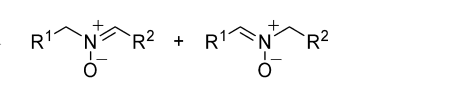 } & \multirow[b]{2}{*}{ Yield $(\%)^{a)}$} \\
\hline & & & $\mathrm{R}^{2}$ & Temp $\left({ }^{\circ} \mathrm{C}\right)$ & Time $(\mathrm{h})$ & Nitrone & \\
\hline 1 & 11a & $\mathrm{Ph}$ & $\mathrm{Ph}$ & $\mathrm{rt}$ & 24 & $12 \mathbf{a}$ & 86 \\
\hline 2 & $11 b$ & $p-\mathrm{CF}_{3}-\mathrm{C}_{6} \mathrm{H}_{4}$ & $p-\mathrm{CF}_{3}-\mathrm{C}_{6} \mathrm{H}_{4}$ & $\mathrm{rt}$ & 24 & $12 b$ & 90 \\
\hline 3 & $11 \mathrm{c}$ & $p-\mathrm{Cl}-\mathrm{C}_{6} \mathrm{H}_{4}$ & $p-\mathrm{Cl}-\mathrm{C}_{6} \mathrm{H}_{4}$ & $\mathrm{rt}$ & 24 & $12 \mathrm{c}$ & 56 \\
\hline 4 & 11d & $p-\mathrm{MeO}-\mathrm{C}_{6} \mathrm{H}_{4}$ & $p-\mathrm{MeO}-\mathrm{C}_{6} \mathrm{H}_{4}$ & $\mathrm{rt}$ & 48 & $12 d$ & 62 \\
\hline 5 & $11 \mathrm{e}$ & $p-\mathrm{MeO}-\mathrm{C}_{6} \mathrm{H}_{4}$ & $p-\mathrm{CF}_{3}-\mathrm{C}_{6} \mathrm{H}_{4}$ & $\mathrm{rt}$ & 24 & $12 \mathrm{e}+12 \mathrm{e}^{\prime}$ & $94\left(\mathbf{1 2 e}+\mathbf{1 2} \mathbf{e}^{\prime}=1.7 / 1\right)$ \\
\hline 6 & $11 \mathrm{f}$ & $\mathrm{Ph}$ & $p-\mathrm{CF}_{3}-\mathrm{C}_{6} \mathrm{H}_{4}$ & $\mathrm{rt}$ & 24 & $12 f+12 f^{\prime}$ & $80\left(\mathbf{1 2 f}+\mathbf{1 2} \mathbf{f}^{\prime}=1.3 / 1\right)$ \\
\hline 7 & $11 \mathrm{~g}$ & $\mathrm{Ph}$ & $p-\mathrm{CN}-\mathrm{C}_{6} \mathrm{H}_{4}$ & 40 & 24 & $12 g+12 g^{\prime}$ & $71\left(\mathbf{1 2} \mathbf{g}+\mathbf{1 2} \mathbf{g}^{\prime}=1.5 / 1\right)$ \\
\hline 8 & $11 \mathrm{~h}$ & $\left(\mathrm{CH}_{3}\right)_{3}$ & $\mathrm{Ph}$ & $\mathrm{rt}$ & 24 & $12 \mathrm{~h}$ & 34 \\
\hline 9 & $11 \mathrm{i}$ & & & $\mathrm{rt}$ & 12 & $12 \mathrm{i}$ & 70 \\
\hline 10 & $11 \mathbf{j}$ & & & $\mathrm{rt}$ & 12 & $12 \mathrm{j}$ & 30 \\
\hline
\end{tabular}

a) Isolated yields.

Table 3. Oxidation of Sulfides to Sulfones with and without PWAA

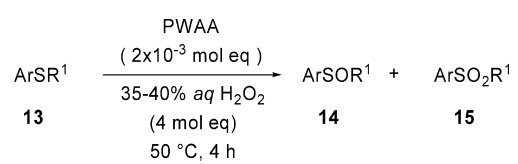

\begin{tabular}{|c|c|c|c|c|}
\hline Entry & 13 & Catalyst & $14(\%)^{a)}$ & $15(\%)^{a)}$ \\
\hline $1^{b)}$ & PhSMe (13a) & PWAA & 3 & 97 \\
\hline $2^{b)}$ & $13 \mathbf{a}$ & - & (74) & (26) \\
\hline 3 & $p-\mathrm{Me}-\mathrm{C}_{6} \mathrm{H}_{4} \mathrm{SMe}(\mathbf{1 3 b})$ & PWAA & 9 & 90 \\
\hline 4 & $13 b$ & - & (71) & (22) \\
\hline 5 & $p-\mathrm{Br}-\mathrm{C}_{6} \mathrm{H}_{4} \mathrm{SMe}(\mathbf{1 3 c})$ & PWAA & 12 & 87 \\
\hline 6 & $13 \mathrm{c}$ & - & (70) & (15) \\
\hline 7 & $p-\mathrm{MeO}-\mathrm{C}_{6} \mathrm{H}_{4} \mathrm{SMe}(\mathbf{1 3 d})$ & PWAA & 6 & 84 \\
\hline 8 & $13 d$ & - & (76) & (24) \\
\hline 9 & PhSEt (13e) & PWAA & 3 & 91 \\
\hline 10 & $13 \mathrm{e}$ & - & (75) & (17) \\
\hline $11^{c)}$ & $\operatorname{Me}(\mathbf{1 3 f})$ & PWAA & 17 & 78 \\
\hline $12^{c)}$ & $13 f$ & - & (9) & $(0)$ \\
\hline 13 & $p$-CHO- $\mathrm{C}_{6} \mathrm{H}_{4} \mathrm{SMe}(\mathbf{1 3 g})$ & PWAA & - & 86 \\
\hline 14 & $13 \mathrm{~g}$ & - & (53) & (33) \\
\hline $15^{c)}$ & $\mathrm{Phs} \widehat{(13 h)}$ & PWAA & 3 & 81 \\
\hline $16^{c)}$ & $13 \mathrm{~h}$ & - & (80) & $(10)$ \\
\hline 17 & $\mathrm{PhS} \frown \mathrm{OH}$ & PWAA & - & Quant \\
\hline 18 & $13 \mathbf{i}$ & - & $(80)$ & (13) \\
\hline 19 & Phs ${ }_{0}^{0}(\mathbf{1 3} \mathbf{j})$ & PWAA & 11 & 71 \\
\hline 20 & $13 \mathbf{j}$ & - & (54) & (Trace) \\
\hline 21 & $\mathrm{PhSPh}(\mathbf{1 3 k})$ & PWAA & 10 & 6 \\
\hline 22 & $13 k$ & - & 4 & (0) \\
\hline
\end{tabular}

The yields of the oxidations without PWAA were in parentheses. a) Isolated yields. b) $3 \mathrm{moleq}$ of $\mathrm{H}_{2} \mathrm{O}_{2}$ was used. c) The reaction was performed for $7 \mathrm{~h}$.

ophile for the Julia olefination ${ }^{69)}$ was converted to the sulfone $\mathbf{1 5 f}$ in $78 \%$ yield (entry 11 ). In this reaction, benzothiazole ring was unaffected through the reaction. The chemoselective oxidation of methylthiobenzaldehyde $(\mathbf{1 3 g})$ proceeded to give $\mathbf{1 5 g}$ in $86 \%$ yield with intactness of formyl group (entry 13). Besides, the oxidation of $\mathbf{1 3 h}$ and $\mathbf{i}$ proceeded efficiently to give $\mathbf{1 5 h}$ and $\mathbf{i}$ in high yields, where the olefin and alcohol

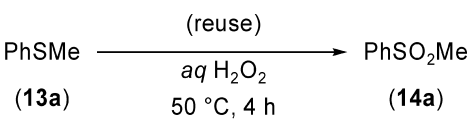

1st use: $97 \%$; 2nd use: $86 \%$; 3rd use: $83 \%$ 4 th use: $88 \%$; 5 th use: $82 \%$

(isolated yields)

Chart 7. Oxidation of 11a Catalyzed by Recycled PWAA

were tolerated and $\beta$-elimination of the alcohol was not observed (entries 15,17 ). Sulfide $\mathbf{1 3} \mathbf{j}$ with a cyclic acetal in the structure was converted to $\mathbf{1 5} \mathbf{j}$, which was the substrate for the preparation of the prostaglandin analogue, in $71 \%$ yield (entry 19). ${ }^{70,71)}$ On the other hand, the reaction of diphenyl sulfide 13k hardly proceeded (entry 21 ).

The recycled activity of PWAA in the oxidation of sulfide 13a was evaluated (Chart 7). The oxidation of 13a was performed under identical conditions, affording 15a in $97 \%$ yield. In the repeated use of the recovered catalyst, PWAA mediated the 2 nd to 5 th cycled runs to give 15a in $82-88 \%$ yields. The reason to reduce yields in the 2 nd cycled run was unclear. One explanation for this might be that PWAA was pulverized and adsorbed onto the reaction vessel so that the efficiency of the reaction was reduced physically. In this respect, it was confirmed that the pulverization did not affect the intrinsic activity of PWAA: the recovered PWAA was analyzed by gel-phase ${ }^{31} \mathrm{P}-\mathrm{NMR}$ to show a broad peak at -13 ppm as well as the PWAA before use. ${ }^{72)}$

As stated above, all the reactions were performed under organic solvent-free conditions. PWAA was insoluble and stable in both aqueous and organic solvents. We expected that PWAA should efficiently catalyze the oxidation in any media. Hence, the activity of PWAA in an organic solvent was investigated. The reactions of 13a to $15 \mathbf{a}$ were carried out with various organic solvents as depicted in Table 4. Similar to the oxidation without organic solvent completed in $4 \mathrm{~h}$ to give $\mathbf{1 5 a}$ in $97 \%$ yield (entry 1), the reaction with aprotic hydrophobic solvents [toluene, $\mathrm{CH}_{2} \mathrm{Cl}_{2}, \mathrm{THF}$, and $\mathrm{Et}_{2} \mathrm{O}$ (entries 2-5)], hydrophilic solvent [DMF (entry 6)], and protic solvent [EtOH (entry 7)] progressed smoothly to furnish 15a 
in high yields. On the contrary, the reaction in toluene proceeded slower to give $\mathbf{1 5 a}$ in $75 \%$. It seems reasonable that both organic solvent-free and -containing systems were effective for this oxidation.

\section{Development of a Novel Solid-Phase Palladium Cata- lyst PdAS and Its Application to Suzuki-Miyaura Reac-} tion

3.1. Preparation of an Assembled Catalyst PdAS We examined a self-assembly between various palladium species and non-cross-linked amphiphilic polymers with phosphine ligands and found that the complexation of $\left(\mathrm{NH}_{4}\right)_{2} \mathrm{PdCl}_{4}$ (18) and poly( $N$-isopropylacrylamide-co-4diphenylstyrylphosphine) (17) afforded a novel palladiumpolymer catalyst PdAS (Pd-acrylamide-styrylphosphine). As shown in Chart $8,{ }^{73,74)}$ random copolymerization of 4 diphenylstyrylphosphine (16) with $12 \mathrm{~mol}$ eq of $N$-isopropylacrylamide (6) in the presence of $4 \mathrm{~mol} \%$ of AIBN gave 17 in $89 \%$ yield. The ratio of the phosphine to the amide units in 17 was determined by ${ }^{1} \mathrm{H}-\mathrm{NMR}$ measurements in $\mathrm{CDCl}_{3}$ to be $1 / 10$, and the phosphine unit was hardly oxidized in this polymerization as shown by ${ }^{31} \mathrm{P}-\mathrm{NMR}$. This ratio of the phosphine to the amide units as $1 / 10$ was reproducible in several experiments. The molecular weight of $\mathbf{1 7}$ was wide-ranging

Table 4. Solvent Effect on the Oxidation Catalyzed by PWAA

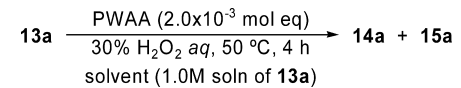

\begin{tabular}{clcc}
\hline \hline Entry & Solvent & $\mathbf{1 2 a}^{a)}$ & $\mathbf{1 3 a}^{a)}$ \\
\hline 1 & -(Neat) & 3 & 97 \\
2 & Toluene & 3 & 75 \\
3 & $\mathrm{CH}_{2} \mathrm{Cl}_{2}$ & 8 & 90 \\
4 & $\mathrm{THF}$ & 8 & 91 \\
5 & $\mathrm{Et} 2$ & - & 96 \\
6 & $\mathrm{DMF}$ & - & 100 \\
7 & $\mathrm{EtOH}$ & - & 99 \\
\hline
\end{tabular}

a) Isolated yields. (ca. 5000-70000) as a result of gel-permeation chromatography relative to polystyrene standards. A self-assembly of $\mathbf{1 7}$ and $\mathbf{1 8}$ was investigated under similar conditions to those for the preparation of $\mathrm{PdCl}_{2}\left(\mathrm{PPh}_{3}\right)_{2}{ }^{75)}$ To a well-stirred solution of 17 ( $3 \mathrm{~mol} \mathrm{eq}$ of phosphine) in THF was added a solution of 18 ( $1 \mathrm{moleq})$ in $\mathrm{H}_{2} \mathrm{O}$. The mixture was stirred for $62 \mathrm{~h}$ at room temperature and the precipitates were formed. After water was added to the suspension, THF was removed at $80^{\circ} \mathrm{C}$ for $4 \mathrm{~h}$ with the Dean-Stark equipment. For removal of a trace amount of unreacted palladium species and polymers, the suspension was stirred at $100^{\circ} \mathrm{C}$ successively in $\mathrm{H}_{2} \mathrm{O}$, in THF, and in $\mathrm{H}_{2} \mathrm{O}$. After drying in vacuo, a dark red solid PdAS 2 was obtained in almost quantitative yield. It was insoluble in water and organic solvents such as acetone, $\mathrm{CH}_{3} \mathrm{OH}, \mathrm{CH}_{2} \mathrm{Cl}_{2}, \mathrm{AcOEt}$, THF, and hexane.

To obtain information on the structure of the catalyst, PdAS 2 was characterized by gel-phase ${ }^{31} \mathrm{P}-\mathrm{NMR}$ in $\mathrm{CDCl}_{3}$. While a peak of 17 was observed at $-2.9 \mathrm{ppm}\left(\mathrm{ArPh}_{2} \underline{\mathrm{P}}\right)$, two broad peaks of PdAS 2 were detected at 32.5 and $26.1 \mathrm{ppm}$, which must be assigned to the signals of $\mathrm{ArPh}_{2} \mathrm{P}=\mathrm{O}$ and $\mathrm{PdCl}_{2}\left(\mathrm{PPh}_{2} \mathrm{Ar}\right)_{2}$, respectively, i.e., the phosphines in $\mathbf{1 7}$ coordinated with palladium to form a $\mathrm{Pd}(\mathrm{II})$. In our preliminary experiments, it was elucidated that the complexation of $\mathbf{1}$ and poly $(N$-isopropylacrylamide) without phosphine units afforded no precipitations. Considering these results, it could be confirmed that the phosphine ligands of $\mathbf{2}$ were the crosslinked structure with palladium (Chart 8).

3.2. Catalytic Activity of PdAS for the SuzukiMiyaura Reaction The catalytic activity of PdAS for the heterogeneous Suzuki-Miyaura reaction ${ }^{76-89)}$ was investigated (Table 5). Since "water" is the most safe, non-toxic, and easily available solvent, numerous attempts have been made in utilizing it to the organic reactions. ${ }^{90,91)}$ While the development of the catalytic system in water has been confronted with many difficulties, PdAS will be a key to develop an efficient system in water owing to its amphiphilicity. Therefore, all the reactions in Tables 5-7 and Chart 9 were performed in water under organic solvent-free conditions. The reaction of iodobenzene (19a) with phenylboronic acid
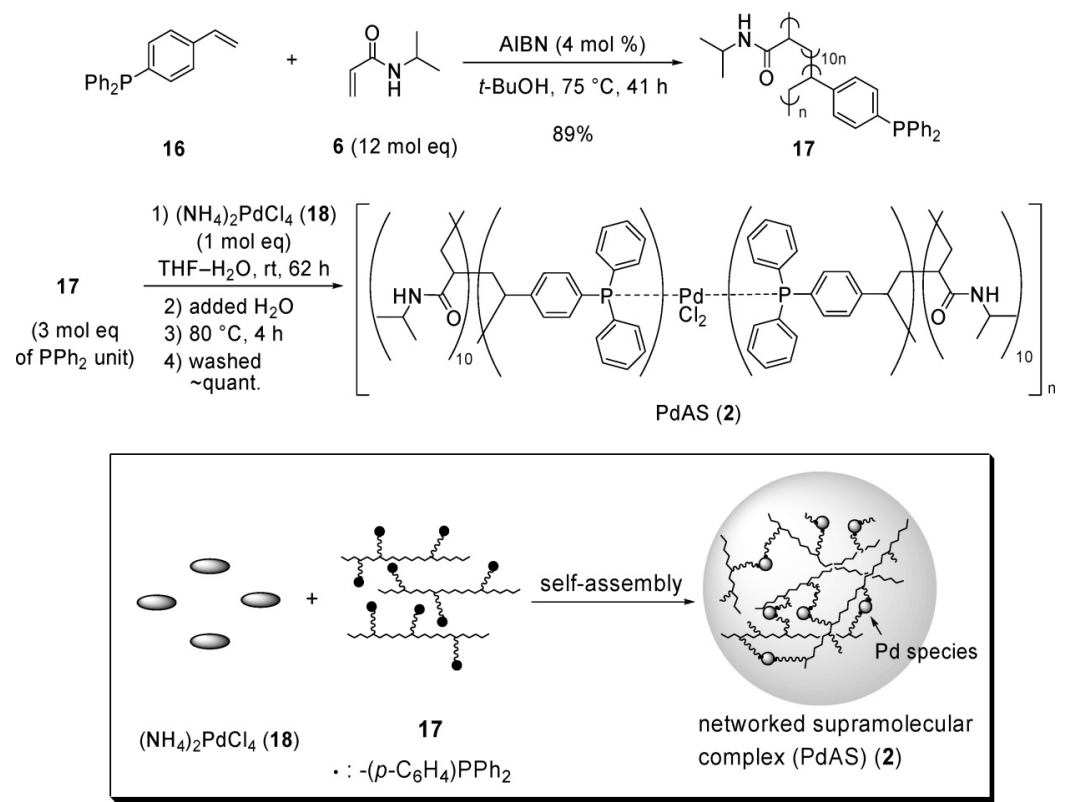

Chart 8. Preparation of an Assembled Catalyst PdAS for the Suzuki-Miyaura Reaction and Its Working Model 
Table 5. The Heterogeneous Suzuki-Miyaura Reaction of Iodobenzene (19a) with Phenylboronic Acid (20a) Catalyzed by $5 \times 10^{-5} \mathrm{moleq}$ of the Recycled Catalyst PdAS

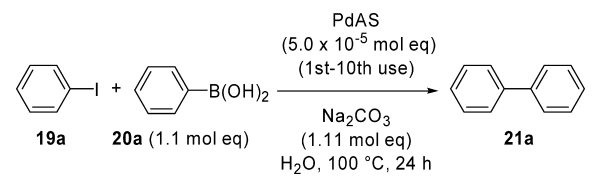

\begin{tabular}{ccrr}
\hline \hline Entry & Catalyst (cycle) & Yield $^{a)}$ & $\begin{array}{c}\text { Turnover number } \\
\text { (TON) }\end{array}$ \\
\hline 1 & 1st cycle & $95 \%$ & 19000 \\
2 & 10 th cycle & $93 \%$ & 18600 \\
3 & $\begin{array}{c}1 \text { st - 10th } \\
\text { consecutive cycle }\end{array}$ & Ave: $95 \%$ & $\begin{array}{r}\text { A total of } \\
190000\end{array}$ \\
\hline
\end{tabular}

a) Isolated by crystallization under organic solvent-free conditions.

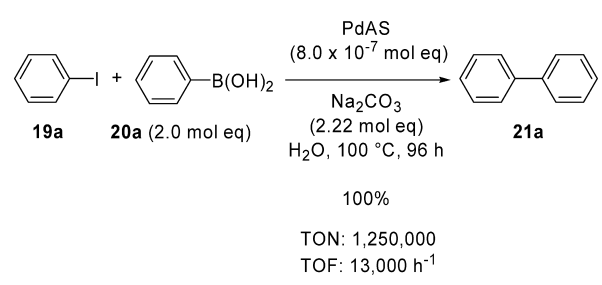

Chart 9. The Heterogeneous Suzuki-Miyaura Reaction Catalyzed by $8.0 \times 10^{-7}$ mol eq of PdAS

(20a) $(1.1 \mathrm{~mol} \mathrm{eq})$ in the presence of $5 \times 10^{-5} \mathrm{~mol} \mathrm{eq}$ of PdAS proceeded efficiently to give biphenyl (21a) in 95\% yield (entry 1) with the TON of PdAS reaching approximately 20000. Leaching of catalytically active species from the supports was often a crucial problem generally. ${ }^{92)}$ In our case, however, the resulting filtrate separated from the reaction mixture had no catalytic activity under identical reaction conditions. Thus, it was confirmed that the catalytic activity observed was due to PdAS itself. ${ }^{93)}$

More importantly, the work-up of this reaction was perfectly performed under organic solvent-free conditions, where water was the only solvent used. After the reaction was completed, the liquid reaction mixture was filtrated with boiling water under an argon atmosphere. PdAS was recovered on a glass filter, ${ }^{94)}$ and the filtrate was cooled to room temperature to give 21a as white crystals with high purity.

In order to examine the activity of PdAS as recyclable catalyst, $5 \times 10^{-5}$ mol eq of PdAS was reused 10 times in the reaction of 19a and 20a. All the reactions were worked up under organic solvent-free conditions as mentioned above. It is noteworthy that PdAS maintains its catalytic activity after reuses (Table 5). The reaction in the 10th cycled run gave $\mathbf{2 1 a}$ in $93 \%$ yield (entry 2 ). The average yield of 21 a in consecutive runs was $95 \%$ (entry 3 ), and the total of TON of PdAS in the 1st to the 10th cycled reactions reached 190000.

We further investigated the limitation of its catalytic activity and found that in less than 1 ppm mol eq of PdAS still catalyzed the reaction efficiently as depicted in Chart 9 . Treatment of 19a with $20 \mathrm{a}$ in the presence of $8 \times 10^{-7}$ mol eq of PdAS afforded 21a quantitatively with high purity. In this case, the turnover number reached 1250000 .

3.3. The Coupling of Aryl Halides with Arylboronic Acids in Water In order to establish the scope of the se- quence, we next examined the reaction of various aryl iodides, aryl bromides, and an aryl triflate with arylboronic acids as depicted in Table 6 . The following reactions except entry 1 were worked up by the traditional method using an organic solvent. ${ }^{95)}$ The reaction of $\mathbf{1 9} \mathbf{a}$ with the electron-rich (20b) or the electron-deficient (20c) arylboronic acids catalyzed by $5 \times 10^{-5} \mathrm{moleq}$ of PdAS afforded the corresponding biaryls $\mathbf{2 1 b}$ and $\mathbf{c}$ in almost quantitative yields (entries 1, 2 ). The reaction of electron-deficient aryl bromides $\mathbf{2 2} \mathbf{a}-\mathbf{d}$ with 20a proceeded smoothly in the presence of $5 \times 10^{-4}$ moleq of PdAS to give the biaryls $21 \mathbf{d}-\mathbf{g}$ in $94-98 \%$ yields (entries 3-6). This system was applicable to the electron-rich aryl bromides 22e and $\mathbf{f}$ (entries 7, 8) and an aryl triflate $\mathbf{2 2 g}$ (entry 9). 4-Bromophenol (20h), 4-bromobenzoic acid (20i) and 3-bromopyridine (20j) were easily converted to the corresponding biaryls (entries 10-12). The reactions using $\mathbf{2 2} \mathbf{h}$ and $\mathbf{i}$, which were soluble in water, were completed in $4 \mathrm{~h}$ to give $\mathbf{2 1 i}$ and $\mathbf{j}$ in 91 and $95 \%$ yield, respectively (entries 10,11 ). It is notable that the reaction in entry 10 could be performed at room temperature under identical reaction conditions to afford $\mathbf{2 1 i}$ in $80 \%$ yield. Substituted arylboronic acids can be used as reactants (entries 13-16). The reaction of the sulfur-containing boronic acid 20d also proceeded smoothly to afford $\mathbf{2 1 m}$ in 95\% yield (entry 14). In general, when the reaction of electron-deficient arylboronic acid is performed in the presence of $\mathrm{Na}_{2} \mathrm{CO}_{3}$ as a base, a critical hydrolysis of arylboronic acid occurs to decrease the yield of the corresponding biaryl. ${ }^{96)}$ However, it was found that the use of $1.1 \mathrm{~mol} \mathrm{eq}$ of the electron-deficient arylboronic acid 20f with 22 e resulted in the biaryl 210 in $84 \%$ yield (entry 16). Furthermore, the product 21 p that is an important intermediate in the synthesis of the angiotensin II antagonists ${ }^{97-99)}$ was prepared by the reaction of 2-bromobenzonitrile (22k) with $p$-tolylboronic acid (20g) (entry 17).

3.4. The Coupling of Alkenyl Halides and Alkenylboronic Acids At this point, we turned our attention to the coupling of alkenyl halides and alkenylboronic acids (Table $7) .{ }^{13)}$ In the presence of $5 \times 10^{-4} \mathrm{~mol}$ eq of PdAS, hexenylboronic acid (23a) was successfully cross-coupled with 19a and 22a to afford 24a and $\mathbf{b}$ in 91 and $86 \%$ yield (entries 1, 2 ). The reaction of aryl bromides $22 \mathbf{a}$ and $\mathbf{c}$ with trans-2phenylvinylboronic acid (23b) also proceeded efficiently (entries 3, 4). Similarly, ethyl cis-3-iodomethacrylate 25a was converted to the corresponding coupling product $24 \mathrm{e}$ in $96 \%$ yield (entry 5). It is interesting to note that $\beta$-bromostyrene (25b) $(E / Z=10 / 1)$ was reacted with $20 b$ to afford $24 f$ in $91 \%$ yield without no isomerization (entry 6). $\alpha$-Bromostyrene (25c) was converted to disubstituted styrene derivatives $\mathbf{2 4 g}$ and $\mathbf{h}$ in 90 and $92 \%$ yield respectively (entries 7,8 ). The coupling of an alkenyl halide with an alkenylboronic acid was successful; conjugated diene 24i was synthesized from 25b and 23a in $81 \%$ yield (entry 9). Both vinyl and allylic bromides in 2,3-dibromopropene $(\mathbf{2 5 d})$ reacted with $3 \mathrm{~mol} \mathrm{eq}$ of $\mathbf{2 0 b}$ to afford the double coupling product $\mathbf{2 4 \mathbf { j }}$ in $70 \%$ yield (entry 10). A screening compound for several GABA uptake inhibitors $\mathbf{2 4} \mathbf{k}^{100,101)}$ was synthesized from $\mathbf{2 5}$ e and 20b in $81 \%$ yield (entry 11 ).

3.5. Stability of PdAS in Organic Solvent Now that we are sure that all the reactions were successfully performed under organic solvent-free conditions, we next deal with sta- 
Table 6. The Heterogeneous Suzuki-Miyaura Reaction of Aryl Iodides, Bromides and Triflate with Arylboronic Acids Catalyzed by PdAS

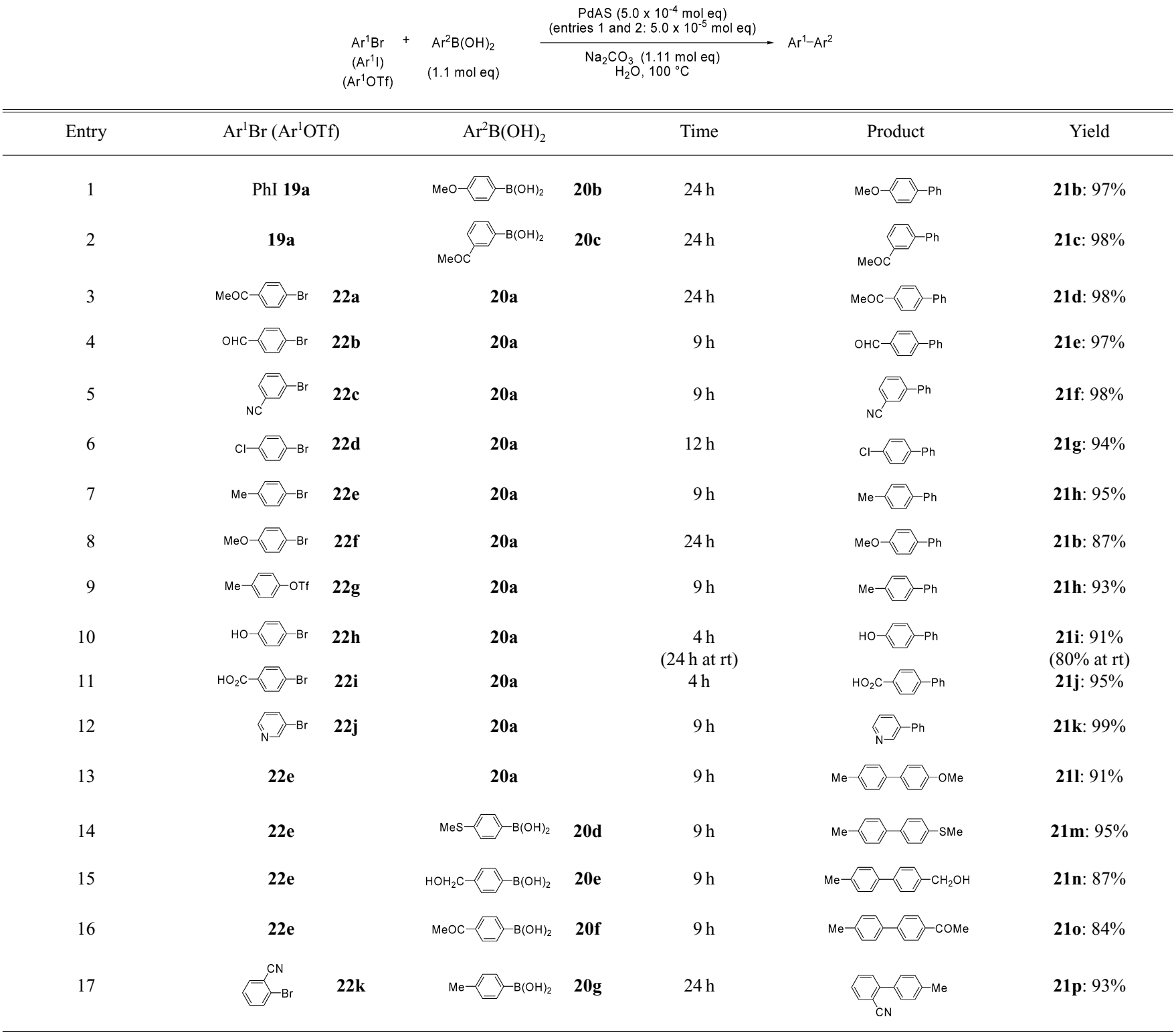

bility of PdAS in organic solvents. During the study on characterization of PdAS, we have observed that PdAS swelled in $\mathrm{CDCl}_{3}$. Therefore we examined the effect of organic solvents on its activity. It was found that all the reactions with several aqueous co-solvents proceeded efficiently (Table 8). While the coupling of 22b with $\mathbf{2 0 a}$ in water afforded $21 \mathbf{e}$ in $95 \%$ yield (entry 1), the reactions in aqueous aprotic solvents (THF, toluene, DMF, 1,4-dioxane, 2-butanone (entries 26)), a protic solvent (2-butanol (entry 7)), and a mixed solvent (ethanol-dimethoxyethane (entry 8)) progressed smoothly, furnishing 21e in approximately $90 \%$ yields. These results indicated that PdAS maintains its catalytic activity in organic solvents.

3.6. The Coupling of Alkyl-9-BBNs in Anhydrous Organic Solvents We further examined the reaction in anhydrous organic solvents. Since the coupling reaction of alkyl9-BBNs is very useful for organic syntheses, we focused on the Suzuki-Miyaura reaction of $s p^{3}$-boranes in anhydrous media. Alkyl-9-BBNs were prepared from an alkene with 9-BBN-H in anhydrous THF and used without any purifica- tion. ${ }^{102)}$ It is notable that PdAS also worked effectively even in anhydrous conditions. As shown in Table 9, the reaction of octyl-9-BBN (26a), prepared from 1-octene and 9-BBN-H in THF, with aryl iodides 19a and b were performed in THF1,4-dioxane $(1: 1),{ }^{103)}$ furnishing 1 -aryloctanes $\mathbf{2 7} \mathbf{a}$ and $\mathbf{b}$ in 95 and $88 \%$ yield, respectively (entries 1,2 ). Electron-deficient and -rich aryl bromides, and alkenyl bromides $\mathbf{2 2 a}, \mathbf{d}, \mathbf{k}$, and 25b were also adequate substrates (entries 3-6). The reactions of phenyethyl-9-BBN gave the corresponding coupling products in more than $90 \%$ yields (entries 7,8 ). Besides, the coupling of an alkenyl halide with an alkyl-9-BBN is among the most important reactions for natural product synthesis. ${ }^{104)}$ Thus, it is noteworthy that the coupling of alkenyl bromides 25b (entry 6), 25e (entry 9), and $25 f$ (entry 10) proceeded efficiently to provide the corresponding products in high yields.

3.7. The Coupling of Benzylic Chlorides Since the catalyst worked efficiently for $s p^{3}$-borane systems, attention was turned to the coupling of $s p^{3}$-halides such as benzylic halides (Table 10). Until now, there are only a few reported 
Table 7. The Heterogeneous Suzuki-Miyaura Reaction of Alkenyl Halides and Alkenylboronic Acids Catalyzed by PdAS

\begin{tabular}{|c|c|c|c|c|c|c|c|}
\hline \multirow[b]{2}{*}{ Entry } & \multirow[b]{2}{*}{ Halid } & \multirow[t]{2}{*}{$\begin{array}{l}R^{1} B \\
\left(R^{1} \mid\right.\end{array}$} & \multirow{2}{*}{$\begin{array}{c}+\mathrm{R}^{2} \mathrm{~B}(\mathrm{OH})_{2} \\
(1.1 \mathrm{~mol} \mathrm{eq}) \\
\text { Boronic acid }\end{array}$} & \multicolumn{2}{|c|}{$\begin{array}{c}\frac{\operatorname{PdAS}\left(5.0 \times 10^{-4} \mathrm{~mol} \mathrm{eq}\right)}{\longrightarrow \mathrm{Na}_{2} \mathrm{CO}_{3}(1.11 \mathrm{~mol} \mathrm{eq})} \\
\mathrm{H}_{2} \mathrm{O}, 100^{\circ} \mathrm{C}\end{array}$} & $R^{1}-R^{2}$ & \multirow[b]{2}{*}{ Yield } \\
\hline & & & & & Time & Product & \\
\hline 1 & $19 a$ & & $\sim_{\mathrm{B}(\mathrm{OH})}$ & ) $23 \mathbf{a}$ & $9 \mathrm{~h}$ & & 24a: $91 \%$ \\
\hline 2 & $22 a$ & & $23 a$ & & $9 \mathrm{~h}$ & & 24b: $86 \%$ \\
\hline 3 & $22 a$ & & $\mathrm{Ph} \cong \mathrm{B}(\mathrm{OH})_{2}$ & $23 b$ & $6 \mathrm{~h}$ & & 24c: $82 \%$ \\
\hline 4 & $22 c$ & & 23b & & $6 \mathrm{~h}$ & & 24d: $82 \%$ \\
\hline 5 & & $25 a$ & $20 b$ & & $6 \mathrm{~h}$ & & 24e: $97 \%$ \\
\hline 6 & 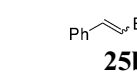 & $(E: Z(10: 1))$ & $20 \mathrm{~b}$ & & $24 \mathrm{~h}$ & & 24f: $91 \%$ \\
\hline 7 & $\mathrm{Ph} \stackrel{\mathrm{Br}}{\mathrm{S}}$ & $25 c$ & $20 \mathrm{~b}$ & & $9 \mathrm{~h}$ & & 24g: $90 \%$ \\
\hline 8 & $25 c$ & & $20 f$ & & $9 \mathrm{~h}$ & & 24h: $92 \%$ \\
\hline 9 & $\mathbf{2 5} \mathbf{b}(E: Z$ & :1)) & $23 a$ & & $5 \mathrm{~h}$ & & $\begin{array}{c}\mathbf{2 4 i}: 81 \% \\
(E: Z(5: 1))\end{array}$ \\
\hline $10^{b)}$ & $\overbrace{B}^{B r}$ & 25d & $20 b^{a)}$ & & $24 \mathrm{~h}$ & & $\mathbf{2 4 j}: 70 \%$ \\
\hline $11^{b)}$ & $\int_{N}^{B r} \sqrt{N}$ & $25 \mathrm{e}$ & $20 \mathrm{~b}$ & & $9 \mathrm{~h}$ & & 24k: 81\% \\
\hline
\end{tabular}

a) 3.0 mol eq of $20 \mathbf{b}$. b) The reaction temperature was $80^{\circ} \mathrm{C}$ and $2.0 \times 10^{-3} \mathrm{~mol}$ eq PdAS was used.

Table 8. The Effects of Organic Solvents as a Co-solvent on the Heterogeneous Suzuki-Miyaura Reaction Catalyzed by PdAS in Water

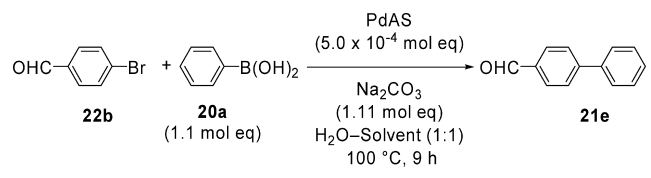

\begin{tabular}{clc}
\hline \hline Entry & \multicolumn{1}{c}{ Co-solvent } & Yield (\%) \\
\hline 1 & \multicolumn{1}{c}{-} & 95 \\
2 & THF & 91 \\
3 & Toluene & 92 \\
4 & DMF & 94 \\
5 & 1,4-Dioxane & 95 \\
6 & 2-Butanone & 89 \\
7 & 2-Butanol & 87 \\
8 & EtOH-DME $(1: 4)$ & 90 \\
\hline
\end{tabular}

examples of the Suzuki-Miyaura reactions of benzylic halides even in the homogeneous system. ${ }^{105-108)}$ The reaction of benzyl chloride with $1.1 \mathrm{moleq}$ of boronic acids was performed in the presence of $5 \times 10^{-4} \mathrm{moleq}$ of $\mathrm{PdAS}$ with $3.0 \mathrm{~mol}$ eq of KF in DME. The coupling of benzyl chloride (28a) with 20b was accomplished in $9 \mathrm{~h}$ to give 29a in $95 \%$ yield (entry 1). ${ }^{109)}$ This result indicated that oxidative addition of a benzylic chloride to PdAS proceeded smoothly. The same reaction of $\mathbf{1 5 a}$ with $2.0 \mathrm{~mol}$ eq of $\mathbf{2 0 b}$ in the presence of $2 \times 10^{-3}$ mol eq of PdAS completed in $1 \mathrm{~h}$ to afford 29a in $92 \%$ yield. The reaction of electron-deficient and -rich arylboronic acids were also converted to the coupling products in more than $90 \%$ yields (entries 2, 3). A series of substituted benzyl chlorides also proved to be good substrates (entries $4-7)$. It is notable that the reaction of 4-chlorobenzyl chloride $\mathbf{2 8 b}$ ) with $\mathbf{2 0 b}$ afforded $\mathbf{2 9 d}$ in $72 \%$ yield and a biscoupling product 29d' in 9\% yield; it is assumed that the oxidative addition of a less reactive aryl chloride to PdAS occurred in this conditions. Furthermore, alkenylboronic acid 23a was coupled with benzylic chloride smoothly (entry 7).

\section{Development of a Novel Solid-Phase Palladium Cata- lyst PdAS-V and Its Application to Mizorogi-Heck Reac- tion}

4.1. PdAS-V vs. PdAS Since PdAS was a highly active and reusable catalyst, we focused on its application to the efficiently recycled system of the Heck reaction. The Heck reaction, the coupling of $s p^{2}$-halides with alkenes promoted by palladium catalysts, is an important reaction for the synthesis of natural products and bioactive compounds as 
Table 9. The Heterogeneous Suzuki-Miyaura Reaction of Alkyl-9-BBNs Catalyzed by PdAS

\begin{tabular}{|c|c|c|c|c|c|c|}
\hline & & $\begin{array}{c}\mathrm{R}^{1}-\mathrm{X} \\
(\mathrm{X}=\mathrm{I}, \mathrm{Br})\end{array}$ & $\begin{array}{c}+\quad \mathrm{R}^{2}-9-\mathrm{BBN} \\
\mathbf{2 6}(1.1 \mathrm{~mol} \text { eq })\end{array}$ & $\begin{array}{c}\mathrm{PdAS}\left(5.0 \times 10^{-4} \mathrm{~mol} \text { eq }\right) \\
\underset{\mathrm{K}_{3} \mathrm{PO}_{4}(3.0 \mathrm{~mol} \mathrm{eq})}{\mathrm{THF}, 1,4-\text { dioxane }}(1: 1) \\
100^{\circ} \mathrm{C}\end{array}$ & $\begin{array}{c}R^{1}-R^{2} \\
27\end{array}$ & \\
\hline Entry & $\mathrm{R}^{1}-\mathrm{X}$ & & $\mathrm{R}^{2}-9-\mathrm{BBN}$ & Time & Product & Yield \\
\hline 1 & $19 \mathrm{a}$ & & $\mathrm{C}_{8} \mathrm{H}_{17}-9-\mathrm{BBN}$ & $1.5 \mathrm{~h}$ & $\mathrm{Ph}-\mathrm{C}_{8} \mathrm{H}_{17}$ & 27a: $95 \%$ \\
\hline 2 & & $19 b$ & $26 a$ & $1.5 \mathrm{~h}$ & & 27b: $88 \%$ \\
\hline 3 & $22 \mathrm{a}$ & & $26 a$ & $1.5 \mathrm{~h}$ & & 27c: $91 \%$ \\
\hline 4 & $t-B u-<$ & 22d & 26a & $10 \mathrm{~h}$ & & 27d: $91 \%$ \\
\hline 5 & & $22 k$ & $26 a$ & $10 \mathrm{~h}$ & $\mathrm{ACOCH}$ & 27e: $93 \%$ \\
\hline 6 & $25 b$ & & 26a & $1.5 \mathrm{~h}$ & & $\begin{array}{c}\text { 27f: } 97 \% \\
(E: Z(8: 1))\end{array}$ \\
\hline 7 & $19 \mathrm{a}$ & & $\mathrm{Ph}\left(\mathrm{CH}_{2}\right)_{2}-9-\mathrm{BBN} 26 \mathrm{t}$ & $10 \mathrm{~h}$ & $\mathrm{Ph}-\left(\mathrm{CH}_{2}\right)_{2} \mathrm{Ph}$ & $27 \mathrm{~g}: 93 \%$ \\
\hline 8 & $19 b$ & & $26 \mathrm{~b}$ & $10 \mathrm{~h}$ & & 27h: $91 \%$ \\
\hline 9 & $\overbrace{N}^{B r} \widehat{N}$ & $25 \mathrm{e}$ & $\mathrm{BnO}_{y Y_{6}^{9-B B N} \quad 26 c}$ & $15 \mathrm{~h}$ & $\widehat{N}$ & 27i: $77 \%$ \\
\hline 10 & $\geqslant-B r$ & $25 f$ & $26 c$ & $15 \mathrm{~h}$ & & $27 \mathbf{j}: 86 \%$ \\
\hline
\end{tabular}

Table 10. The Heterogeneous Suzuki-Miyaura Reaction of Benzyl Halides Catalyzed by PdAS

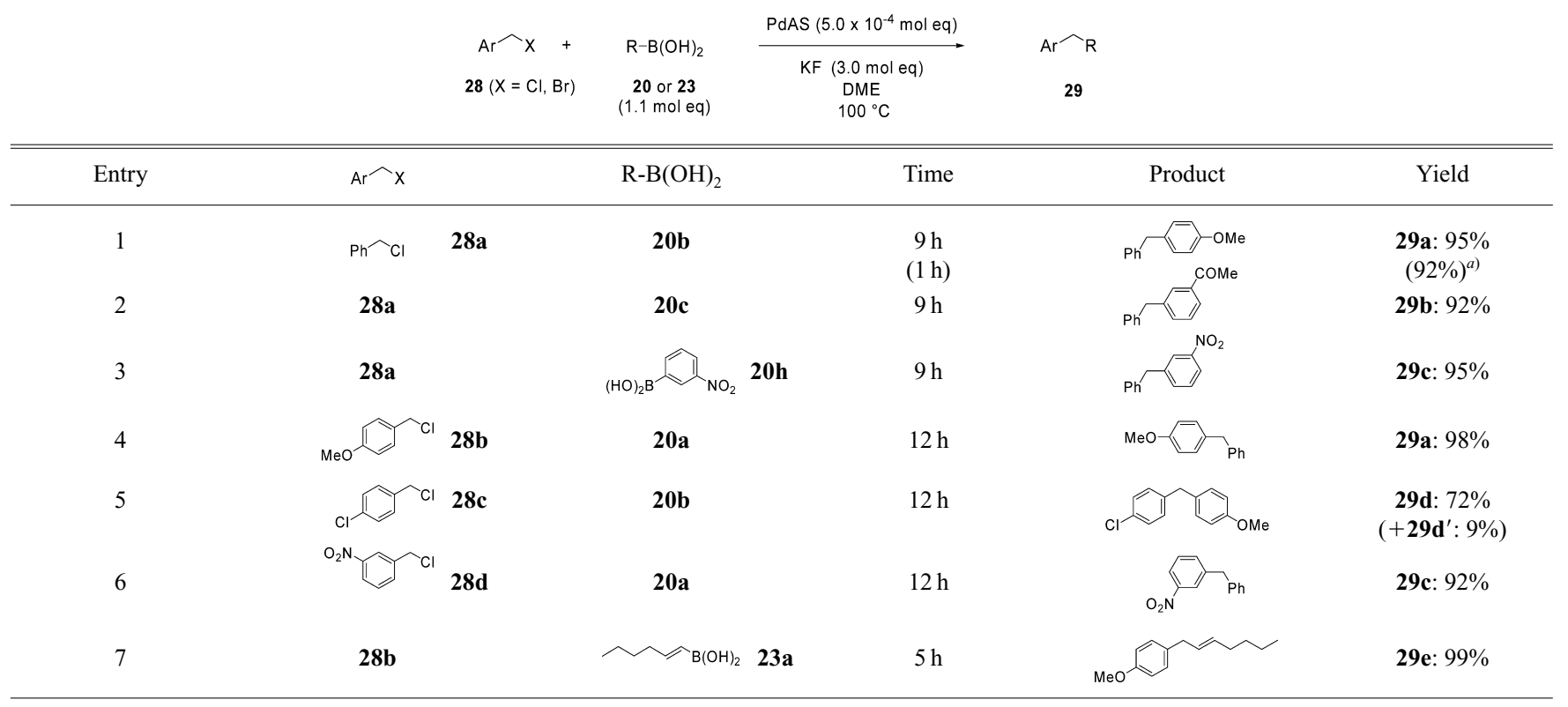

a) The reaction was performed with $2.0 \mathrm{~mol}$ eq of $\mathbf{2 0 b}$ in the presence of $2 \times 10^{-3}$ mol eq of PdAS. $\mathbf{2 9} \mathbf{d}^{\prime}$

well as for the industrial process chemistry. ${ }^{110-113)}$ Although many efforts to prepare solid-phase catalysts for the Heck reaction have been made, homogeneous catalytic systems have advantages on catalytic activity. ${ }^{11-122)}$ In fact, it was known that designing recyclable system for the Heck reaction was more challenging than that for the Suzuki-Miyaura reaction. These catalysts were less stable under the Heck reaction condition, and thus often decompose physically or chemically. For example, resulting salts accumulated in the reaction lead to degradation of the catalytic system and choke of catalysts under the Heck conditions. Besides, the reductive elimination of phosphonium cation causes depletion of phosphine-containing palladium catalysts.

While a preliminary investigation by using PdAS 2 was carried out, it was concluded that PdAS was not so effective owing to its pulverization under the recycled condition of the Heck reaction. We supposed that cross-linking in PdAS was not sufficient to preserve physical strength for the Heck reaction. This hypothesis struck us that a more cross-linked palladium catalyst should enhance the physical strength and the 


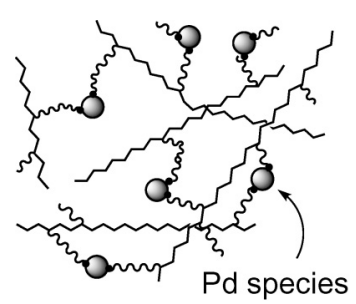

PdAS

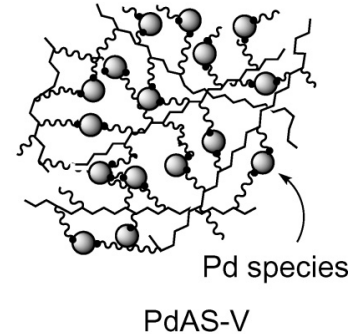

Fig. 3. Working Model of PdAS and PdAS-V

stability. Based on our working hypothesis, I present here the detail of the development of PdAS-V and a highly efficient and recyclable system for the heterogeneous Heck reaction. It is found that PdAS-V showed good stability not only in toluene but also in water, and thus both solvents were suitable for this reaction of versatile substrates such as alkylacrylates, styrenes, and acrylic acid with aryl iodides. It is noteworthy that employment of $8.0 \times 10^{-7}-5.0 \times 10^{-5} \mathrm{~mol} \mathrm{eq}$ of PdAS-V facilitated the recycled system of the Heck reaction with TON up to 1150000 and TOF up to $12000 \mathrm{~h}^{-1}$. PdAS-V was reused five times without any decrease in its activity. Furthermore, the efficient synthesis of resveratrol, a promising COX-II inhibitor, was achieved via the PdAS-V-promoted Heck reaction.

The difference of PdAS-V and PdAS was that the ratio of the $N$-isopropylacrylamide unit to the phosphine unit was $5 / 1$ in PdAS-V while that in PdAS was 10/1. Theoretically, the polymers in PdAS-V were cross-linked eight-fold more than those in PdAS per unit volume, and thus the amount of palladium in PdAS-V increased eight-fold over PdAS per unit content (Fig. 3). This implied that physical strength of PdAS$\mathrm{V}$ was superior to that of PdAS, so that PdAS-V was expected to be prevented from pulverization under the Heck reaction conditions.

4.2. The Catalytic Activity of PdAS-V To check the potency of PdAS-V for the Heck reaction, PdAS-V was treated with the reaction of $19 \mathrm{a}$ with $1.5 \mathrm{~mol}$ eq of $\mathbf{3 0 a}$ in the presence of $\mathrm{Et}_{3} \mathrm{~N}$ in toluene at $100^{\circ} \mathrm{C}$ (Table 1). The results agreed with our working hypothesis that PdAS-V was a highly active and reusable catalyst; the employment of $5.0 \times 10^{-5} \mathrm{~mol}$ eq of PdAS-V in the 5th cycled run afforded 31a in 95\% yield with TON being 19000 (entry 5). PdAS-V was recycled five times without any loss of its activity. The average yield of five runs was $94 \%$. A total turnover number of PdAS-V in the 1 st to the 5th cycled runs was 94000, and the average of TOF was $1250 \mathrm{~h}^{-1}$.

Since the recycled ability and high TON of PdAS-V was achieved in the Heck reaction, we further investigate the limitation of its catalytic activity. It was found that less than $1 \mathrm{ppm}$ mol eq of PdAS-V catalyzed the coupling efficiently as shown in Chart 10. The employment of $8 \times 10^{-7} \mathrm{moleq}$ of PdAS-V in the coupling of 19a $(1.37 \mathrm{~mol} ; 153 \mathrm{ml})$ with $\mathbf{3 0 b}$ $(2.06 \mathrm{~mol} ; 186 \mathrm{ml})$ for $96 \mathrm{~h}$ provided $31 \mathrm{~b}(1.27 \mathrm{~mol} ; 205 \mathrm{~g})$ in $92 \%$ yield, isolated by crystallization. It is notable that PdAS-V promoted the reaction on a scale of more than one mol with TON and TOF in its reaction reaching 1150000 and $12000 \mathrm{~h}^{-1}$ respectively. That is, PdAS-V was the most active solid-phase catalyst for the Heck reaction. As far as we know, this is the highest TON value by the reusable catalysts for the Heck reaction.
Table 11. Recycling of PdAS-V for the Heck Reaction

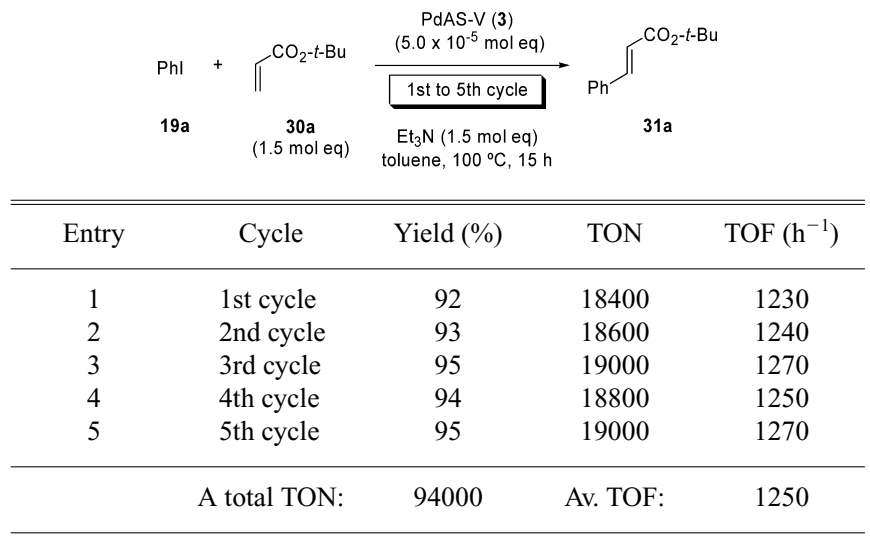

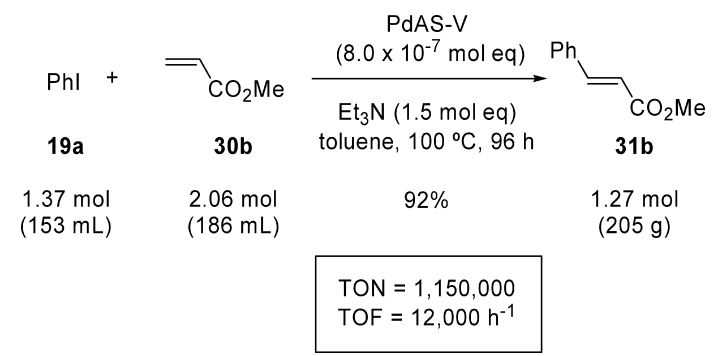

Chart 10. The Heterogeneous Heck Reaction Catalyzed by $8 \times 10^{-7} \mathrm{~mol} \mathrm{eq}$ of PdAS-V

The product $\mathbf{3 1 b}$ was purified by crystallization.

4.3. The Heck Reaction of Aryl Iodides with Acrylates in Toluene In order to establish the scope of the sequence as depicted in Table 12, the coupling of various aryl halides with acrylates was investigated. All the reactions in Table 12 were performed under identical conditions as in Table 11: aryl iodide ( $1 \mathrm{~mol} \mathrm{eq})$, alkene ( $1.5 \mathrm{~mol} \mathrm{eq})$, PdAS-V $\left(5.0 \times 10^{-5} \mathrm{~mol} \mathrm{eq}\right), \mathrm{Et}_{3} \mathrm{~N}(1.5 \mathrm{moleq})$ in toluene at $100^{\circ} \mathrm{C}$. Full conversions were achieved for these couplings in the presence of PdAS-V to afford cinnamic esters in high yields with TON and TOF of PdAS-V reached approximately 20000 and $1000 \mathrm{~h}^{-1}$, respectively. The reaction of 19a with alkylacrylates $30 \mathrm{~b}$ - e proceeded in $5-20 \mathrm{~h}$ to give the corresponding couplings in $93-98 \%$ yields (entries $1-4$ ). It is notable that the coupling of hexafluoroisopropyl acrylate (31d), an electron-deficient olefin, proceeded much faster and completed in $5 \mathrm{~h}$ to furnish 31e in $95 \%$ yield (entry 4 ). Electron-deficient aryl iodides such as ethoxycarbonyl-, acetoxy-, chloro-, and fluoro-substituted iodobenzenes were also converted to 31f $-\mathbf{i}$ in more than $90 \%$ yields (entries $5-8$ ). The reaction system was applicable to the reaction of an electron-rich iodoarene (entry 9). Moreover, the coupling of ortho-substituted aryl iodides, sterically hindered substrate, proceeded to afford the corresponding products in high yields while it was slower (entries 10,11). Interestingly, the reactions of acrylic acid (32) in toluene were faster than that of alkyl acrylates to afford cinnamic acids 33a and $\mathbf{b}$ in $93 \%$ and $90 \%$ yields.

4.4. The Heck Reaction of Aryl Iodides with Styrenes in Toluene PdAS-V was applicable to the coupling of styrene derivatives. The reaction conditions were identical with that in the reaction of acrylates. Aryl iodides with styrenes were also converted smoothly to the corresponding 
Table 12. The Heck Reaction of Aryl Iodides with Acrylates

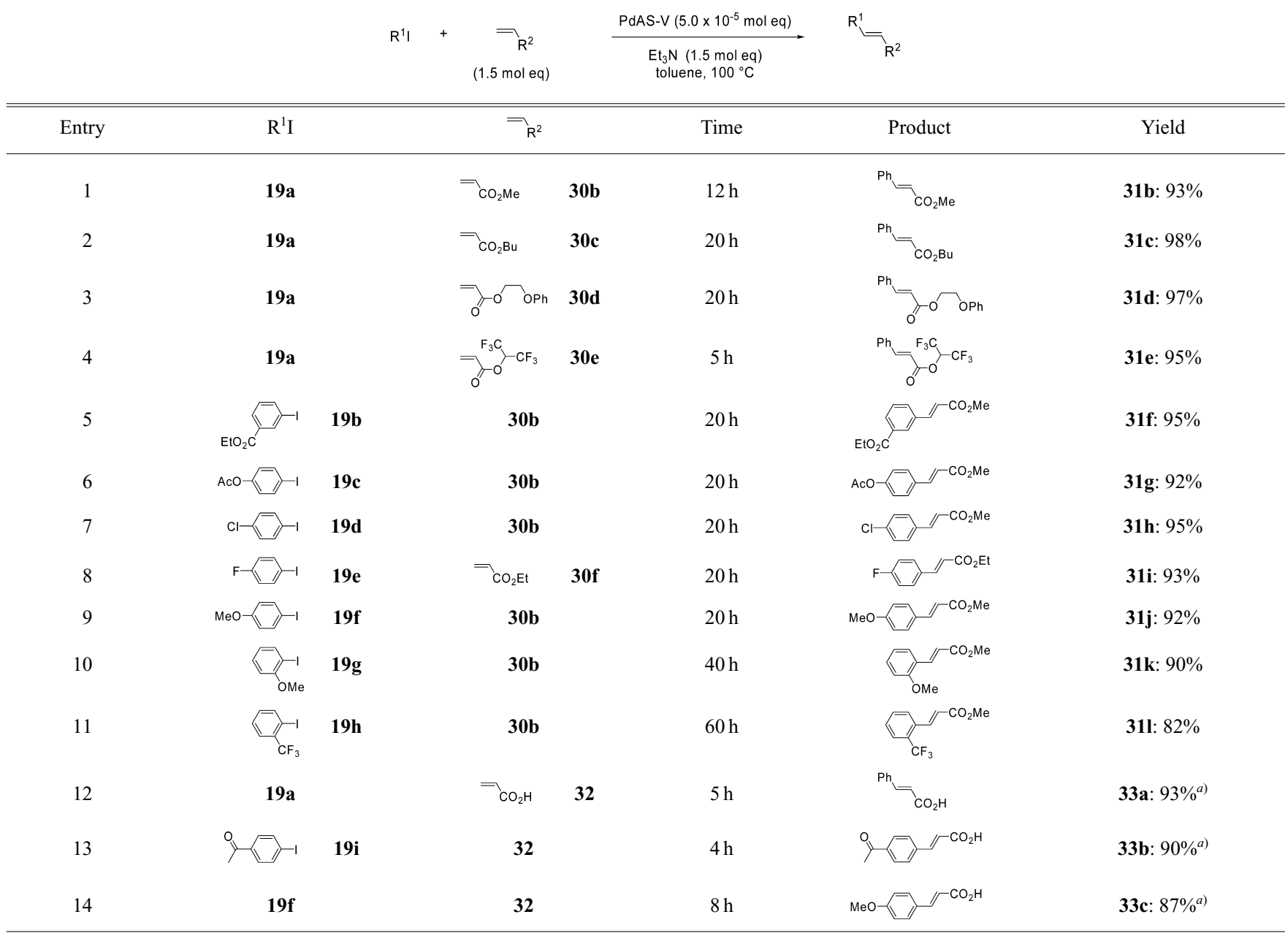

a) The product was purified by recrystallization without column chromatography.

stilbenes in high yields with TON and TON being approximately 20000 and $1000 \mathrm{~h}^{-1}$ (Table 13). When the reaction of iodobenzene (19a) with styrene (34a) was carried out, stilbene (35a) was obtained in 90\% yield. Both electron-deficient (entries 2-4) and -donating (entry 5) aryl iodides were efficiently coupled with $\mathbf{3 4 a}$ to provided the corresponding coupling products $\mathbf{3 5} \mathbf{b}-\mathbf{e}$ in high yields. Besides, the electron-deficient and -donating styrenes $\mathbf{3 4 b}-\mathbf{d}$ were also useful reactants to give 35c - e in approximately $90 \%$ yields (entries 6-8).

4.5. The Heck Reaction in Water All the reactions above mentioned were performed in toluene. Since PdAS-V was composed of an amphiphilic polymer, it was expected that PdAS-V was also stable and work in water. Water is inexpensive, nontoxic, nonflammable, and easily available solvent. It nowadays receives much attention as a reaction solvent, although it has not been commonly used because palladium catalysts were generally unstable in water and hydrophobic substrates were insoluble. Thus, the heterogeneous Heck reaction in water was investigated as shown in Table 14. ${ }^{123-126)}$ We were fueled by finding that PdAS-V has a good stability and activity even in water. The coupling of 19a with acrylic acid (32) proceeded smoothly in $6 \mathrm{~h}$ to result in the formation of cinnamic acid (33a) in 95\% yield (entry 1). Substituted aryl iodides including an ortho-substituted aryl iodide were also appropriate substrates in these couplings (entries 2-7). It was notable that styrene (34a) was also a useful reactant in water while both aryl iodides and styrene were not dissolved in water (entries 8, 9). This result suggested that dispersion of reagents in water might be effective for promoting the reaction.

4.6. Efficient Synthesis of Resveratrol via the Heck Reaction by PdAS-V To demonstrate the utility of PdAS$\mathrm{V}$ for the synthesis of bioactive compounds, resveratrol (33h) was synthesized via the heterogeneous Heck reaction. Resveratrol is a new type antitumor agent that can inhibit all three stages of cancer by inducing quinone reductase activity, inhibiting cyclooxygenase-2 (COX-2), and inducing the expression of nitroblue tetazolium reduction activity. Furthermore, it can inhibit the development of cardiovasacular disease through its ability as an antioxidant to inhibit platelet aggregation and eicosanoid synthesis and its ability to modulate lipoprotein metabolism. ${ }^{127-130)}$ However, it is isolated from natural sources in trace amounts, ${ }^{130}$ ) so that efficient chemical syntheses of $\mathbf{3 3 h}$ are required. ${ }^{131,132)}$ The starting materials 4-iodophenol (19j) and 3,5-dihydroxystyrene $(\mathbf{3 4 e})^{133)}$ were protected by benzoyl group to afford $\mathbf{1 9 k}$ and $34 f$ in 82 and $87 \%$ yield respectively. The heterogeneous Heck reaction $^{12)}$ of aryl iodide $\mathbf{1 9 k}$ and alkene $\mathbf{3 4 f}$ proceeded smoothly in the presence of PdAS-V to furnish the coupling 
Table 13. The Heck Reaction of Aryl Iodides with Styrenes

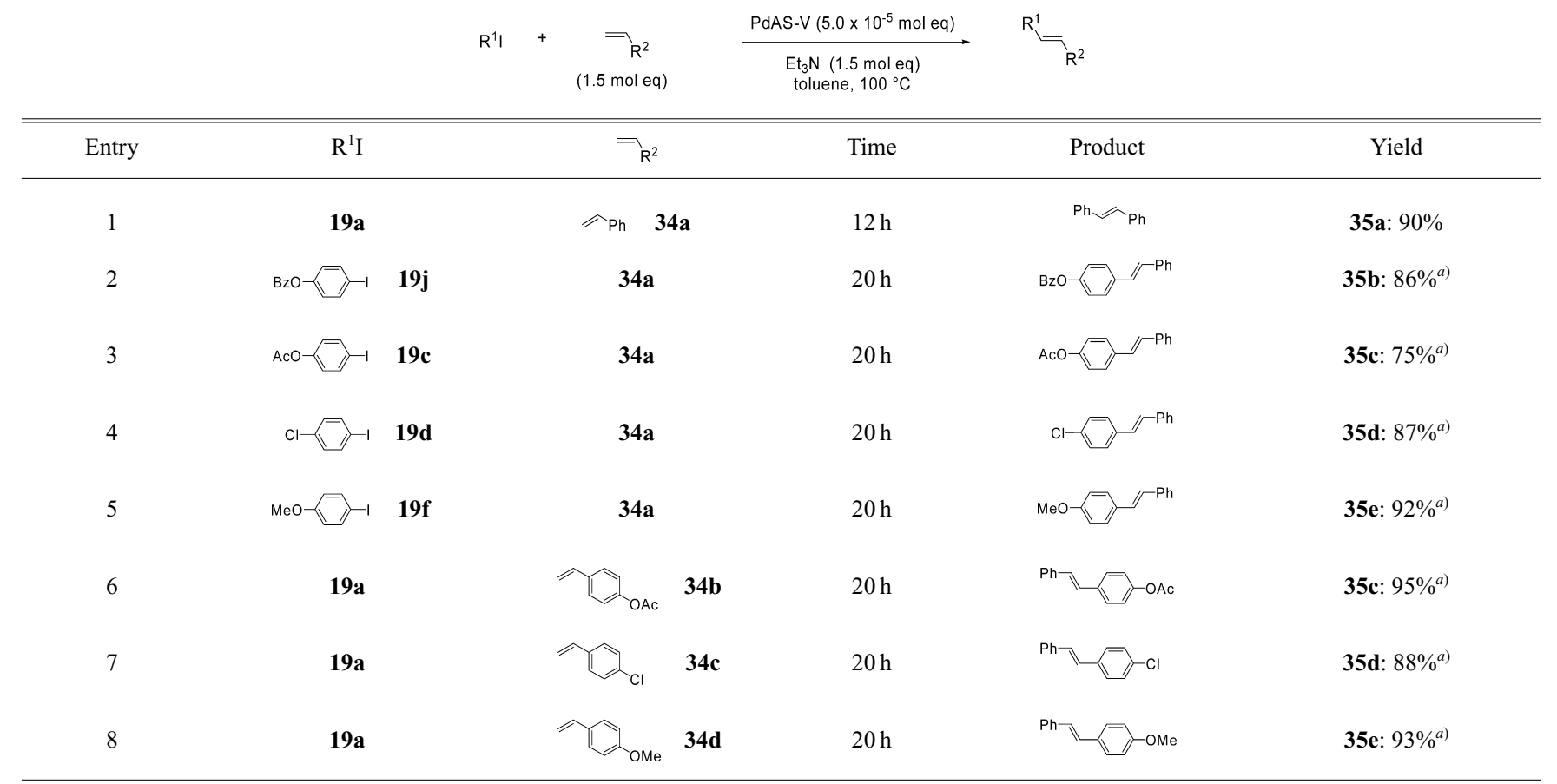

a) These products were purified by recrystallization without column chromatography.

Table 14. The Heck Reaction in Water

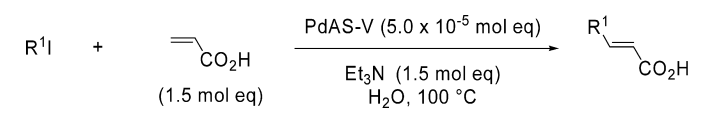

\begin{tabular}{|c|c|c|c|c|c|c|c|}
\hline Entry & $\mathrm{R}^{1} \mathrm{I}$ & & $\bar{R}_{\mathrm{R}}$ & & Time & Product & Yield $^{a)}$ \\
\hline 1 & & $19 a$ & $=\mathrm{CO}_{2} \mathrm{H}$ & 32 & $6 \mathrm{~h}$ & $\mathrm{Ph}-/{ }^{-\mathrm{CO}_{2} \mathrm{H}}$ & 33a: $94 \%$ \\
\hline 2 & & 19d & 32 & & $6 \mathrm{~h}$ & $-\mathrm{CO}_{2} \mathrm{H}$ & 33d: $91 \%$ \\
\hline 3 & & $19 i$ & 32 & & $4 \mathrm{~h}$ & & 33b: $91 \%$ \\
\hline 4 & & $19 k$ & 32 & & $6 \mathrm{~h}$ & & 33e: $94 \%$ \\
\hline 5 & & $19 f$ & 32 & & $24 \mathrm{~h}$ & & 33c: $88 \%$ \\
\hline 6 & & $19 \mathrm{~g}$ & 32 & & $24 \mathrm{~h}$ & & 33f: $95 \%$ \\
\hline 7 & & 191 & 32 & & $8 \mathrm{~h}$ & & 33g: $92 \%$ \\
\hline 8 & $19 \mathrm{a}$ & & $\geqslant$ & $34 a$ & $36 \mathrm{~h}$ & $\mathrm{Ph}-I^{\mathrm{Ph}}$ & 33a: $76 \%$ \\
\hline 9 & & $19 \mathrm{i}$ & $34 a$ & & $30 \mathrm{~h}$ & & 33f: $97 \%$ \\
\hline
\end{tabular}

a) These products were purified by crystallization without column chromatography.

33g in $93 \%$ yield. Deprotection of $\mathbf{3 3 g}$ over NaOMe in THF and $\mathrm{MeOH}$ provided resveratrol (33h) in $98 \%$ yield. The total yield of resveratrol from commercially available $\mathbf{1 9} \mathbf{j}$ was $75 \%$ in 3 steps.

\section{Development of a Novel Solid-Phase Asymmetric Ti-} tanium Catalyst TiSS and Its Application to Enantioselective Carbonyl-ene Reaction

Since this self-assembled catalyst exhibited great potentiality, we tried applying this concept to asymmetric synthesis
(Chart 12). ${ }^{134-137)}$ Hereby, I present development of new chiral catalysts by our methodology and their application to an asymmetric carbonyl-ene reaction. ${ }^{138-140)}$ It is noteworthy that one of the catalysts can be reused five times with retention of its activity and enantioselectivity.

Recently, Nakai and co-authors reported an excellent asymmetric carbonyl-ene reaction catalyzed by a bimetallic titanium complex, in which two binaphthols were bridged by $\mu$-oxodititanium 36 (Fig. 4). ${ }^{138)}$ They noted that the reaction of $\alpha$-methylstyrene with methyl glyoxylate was carried out in 


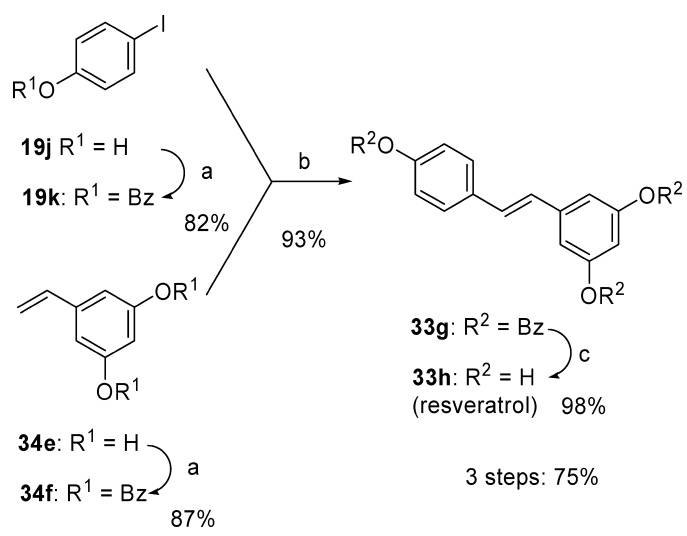

Reagents and conditions: a) $\mathrm{BzCl}$, pyridine, $\mathrm{CH}_{2} \mathrm{Cl}_{2}, 0^{\circ} \mathrm{C}$; (b) $\mathbf{1 9 k}$ (1 mol eq), $\mathbf{3 4 f}$ (1.5 mol eq), PdAS-V $\left(5 \times 10^{-4} \mathrm{~mol} \mathrm{eq}\right), \mathrm{Et}_{3} \mathrm{~N}(1.5 \mathrm{~mol} \mathrm{eq})$, toluene, $100^{\circ} \mathrm{C}, 12 \mathrm{~h}$; (c) $\mathrm{NaOMe}$, THF-MeOH, $50^{\circ} \mathrm{C}, 5 \mathrm{~h}$.

Chart 11. Efficient Synthesis of Resveratrol via the Heck Reaction by PdAS-V

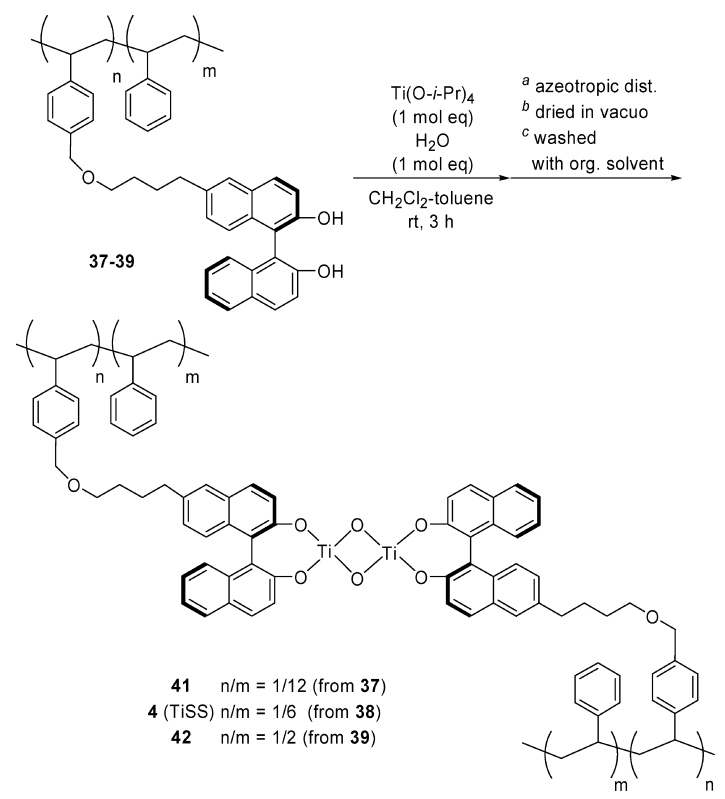

Chart 12

the presence of $5 \mathrm{~mol} \%$ of the titanium complex in $\mathrm{CH}_{2} \mathrm{Cl}_{2}$ at $-30{ }^{\circ} \mathrm{C}$ for $3 \mathrm{~h}$ to provide the corresponding product in $93 \%$ yield with $98 \%$ ee. We envisioned that this homogeneous catalyst would be applicable to the self-assembled and insoluble counterpart, wherein binaphthol moieties bound to noncross-linked copolymer backbones would be crossbridged by $\mu$-oxodititanium. Therefore, we selected $(R)-1,1^{\prime}$-bi-2-naphthol (BINOL) as a chiral ligand moiety. First, a titanium catalyst was made from poly( $N$-isopropylacrylamide) with $(R)$ BINOL. However, the carbonyl-ene reaction in the presence of this catalyst provided the corresponding product in low yield with poor ee. This result suggested that a component of the non-cross-linked copolymer backbones might affect the catalytic activity and enantioselectivity. Thus, after investigating several non-cross-linked copolymer backbones, we found the polystyrene copolymers $\mathbf{3 7 - 3 9}$ to be effective. These 37-39 were prepared from 40 via etherification with 4-vinylbenzyl chloride, random copolymerization with styrene, and deprotection of the methoxymethyl groups, suc-

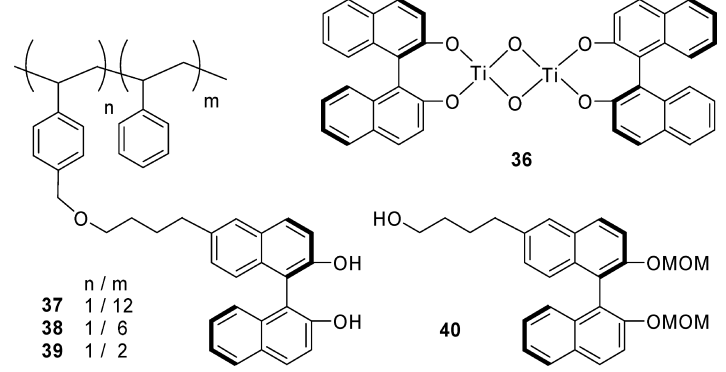

Fig. 4

Table 15. Surveying Potency of Complexes 41, 4, and $\mathbf{4 2}$ as Chiral Catalysts for an Enantioselective Carbonyl-ene Reaction

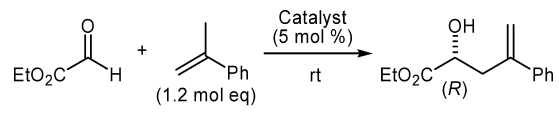

$43 \quad 44 \quad 45$

\begin{tabular}{|c|c|c|c|c|c|}
\hline Entry & Catalyst & Solvent & Time (h) & Yield $(\%)^{a)}$ & ee $(\%)^{b)}$ \\
\hline 1 & 41 & $\mathrm{CH}_{2} \mathrm{Cl}_{2}$ & 48 & 49 & 49 \\
\hline 2 & 4 & $\mathrm{CH}_{2} \mathrm{Cl}_{2}$ & 60 & 55 & 58 \\
\hline 3 & $\mathbf{4 2}^{c)}$ & $\mathrm{CH}_{2} \mathrm{Cl}_{2}$ & 14 & 87 & 56 \\
\hline 4 & 4 & THF & 60 & Trace & N.D. ${ }^{d)}$ \\
\hline 5 & 4 & $\mathrm{PhMe}$ & 60 & 56 & 59 \\
\hline 6 & 4 & $\mathrm{Et}_{2} \mathrm{O}$ & 60 & 68 & 84 \\
\hline
\end{tabular}

a) Isolated yield after purification by column chromatography. b) Enantiomeric excess was determined by HPLC analysis using DAICEL CHIRALPAK AS. c) Compound 45 was obtained in $26 \%$ yield with $36 \%$ ee by reused 42 which was recovered after the reaction in entry $3 .{ }^{141)} d$ ) N.D. $=$ not determined.

cessively. They were easily soluble polymers in $\mathrm{CH}_{2} \mathrm{Cl}_{2}$, and the ratio of $\mathrm{n} / \mathrm{m}$ of $37-39$ could be determined by ${ }^{1} \mathrm{H}-\mathrm{NMR}$ in $\mathrm{CDCl}_{3}$.

With the chiral copolymers in hand, catalysts $\mathbf{4 1}, 4$ (TiSS), and 42 were prepared by a self-assembly of $37-39$, Ti(O- $i-$ $\mathrm{Pr})_{4}$, and $\mathrm{H}_{2} \mathrm{O}$ based on Nakai's conditions for $\mathbf{3 6}^{138}$ ) (Chart 12). Experimental procedure for the synthesis of TiSS was as follows: To a solution of $\mathbf{3 8}(0.120 \mathrm{mmol}$ as a BINOL unit) in $\mathrm{CH}_{2} \mathrm{Cl}_{2}(2.0 \mathrm{ml})$ was added a solution of $\mathrm{Ti}(\mathrm{O}-i-\mathrm{Pr})_{4}$ $(0.120 \mathrm{mmol})$ in toluene $(1.2 \mathrm{ml})$ and $\mathrm{H}_{2} \mathrm{O}(0.120 \mathrm{mmol})$ in $\mathrm{CH}_{2} \mathrm{Cl}_{2}(12 \mathrm{ml})$. The solution was stirred at room temperature for $3 \mathrm{~h}$ to give reddish precipitates. The solvents were removed by azeotropic distillation at $110^{\circ} \mathrm{C}$ for $1 \mathrm{~h}$, and evaporated at $110^{\circ} \mathrm{C}$ under reduced pressure for $1 \mathrm{~h}$. The residue was dried in vacuo at room temperature for $14 \mathrm{~h}$, and washed with $\mathrm{Et}_{2} \mathrm{O}(2 \times 2 \mathrm{ml})$ to give dark reddish lumps 4. As predicted, $\mathbf{4 1}, \mathbf{4}$, and $\mathbf{4 2}$ were insoluble in organic solvents such as $\mathrm{CH}_{2} \mathrm{Cl}_{2}$, THF, PhMe and $\mathrm{Et}_{2} \mathrm{O}$.

To survey the potency of complexes $\mathbf{4 1}, \mathbf{4}$, and $\mathbf{4 2}$ as catalysts, we applied these catalysts to a catalytic enantioselective carbonyl-ene reaction (Table 15). When the reaction of ethyl glyoxylate (43) and $1.2 \mathrm{moleq}$ of $\alpha$-methylstyrene (44) was carried out with $5 \mathrm{~mol} \%$ of $\mathbf{4 1}, \mathbf{4}$, and $\mathbf{4 2}$ in $\mathrm{CH}_{2} \mathrm{Cl}_{2}$ at $-30{ }^{\circ} \mathrm{C}$, the Nakai reaction conditions, ${ }^{138)}$ only a trace amount of $\mathbf{4 5}$ was yielded. However, we were pleased to find that the reaction proceeded rather easily at room temperature to give $\mathbf{4 5}$ in moderate yield with modest ee (entries $1-3$ ). It was found that the solvents influenced the enantioselectivity in this reaction (entries 2, 4-6). When diethyl ether was used as a solvent, $\mathbf{4 5}$ was obtained in $68 \%$ yield with $84 \%$ ee 
Table 16. Recyclable Catalysis Promoted by 4 (TiSS)

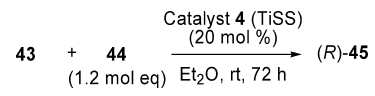

\begin{tabular}{cccc}
\hline \hline Entry & Catalyst & Yield (\%) & ee (\%) \\
\hline 1 & 1st use & 85 & $88^{a)}$ \\
2 & 2nd use & 83 & 88 \\
3 & 3rd use & 79 & 87 \\
4 & 4th use & 77 & 85 \\
5 & 5th use & 86 & 81 \\
\hline
\end{tabular}

a) $[\alpha]_{\mathrm{D}}^{26}-20.1^{\circ}\left(\mathrm{CHCl}_{3}, c=0.75\right)\left(\right.$ lit. $[\alpha]_{\mathrm{D}}^{20}-22.2^{\circ}\left(\mathrm{CHCl}_{3}, c=1.9,96.3 \%\right.$ ee $\left.\left.)\right) .^{144}\right)$

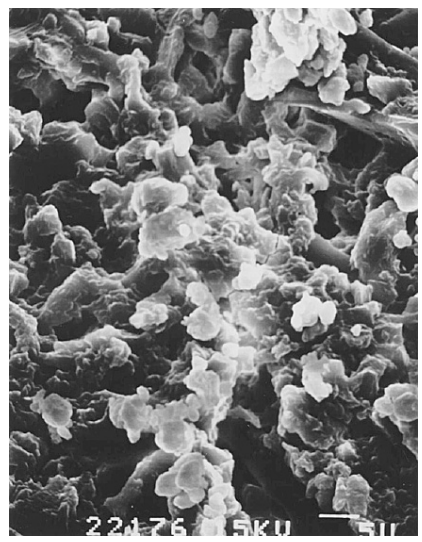

Fig. 5. A Scanning Electron Micrograph (SEM) of TiSS Scale bar: $5 \mu \mathrm{m}$.

(entry 6), whereas $\mathrm{CH}_{2} \mathrm{Cl}_{2}$ and $\mathrm{PhMe}$ gave 45 with moderate ee, and THF afforded only a trace amount of $45 .{ }^{142)}$ It is interesting that the highest enantioselectivity was achieved at room temperature by using TiSS 4.

Furthermore, TiSS 4 was found to be recoverable and reusable (Table 16): when the reaction of $\mathbf{4 3}$ and $1.2 \mathrm{moleq}$ of 44 was performed in the presence of $20 \mathrm{~mol} \%$ of 4 at room temperature for $72 \mathrm{~h}, \mathbf{4 5}$ was given in $85 \%$ yield with $88 \%$ ee (entry 1). The catalyst was reused without further treatment after recovery by filtration. In the repeated use of the recovered catalyst, 45 was obtained in $83 \%$ yield with $88 \%$ ee (entry 2). Again, the recovered catalyst was reused; that is, the third, fourth and fifth reactions afforded $\mathbf{4 5}$ in $79 \%$ yield with $87 \%$ ee, in $77 \%$ yield $85 \%$ ee, and in $86 \%$ yield with $81 \%$ ee, respectively (entries $3-5$ ). ${ }^{143)}$

A scanning electron microscope (SEM) study was made to obtain further information on the catalyst (Fig. 5). TiSS was treated with gold vapor by a sputter coating method. The SEM picture showed the presence of many prominences, which were approximately $1-10 \mu \mathrm{m}$ in length. The surface of 4 is now being investigated to clarify the structure and recognition mechanism.

\section{Conclusion}

Highly active and reusable catalysts have been successfully developed by self-assembly process of linear amphiphilic polymer ligands with inorganic species, affording insoluble supramolecular complexes. Thus, PWAA 1 prepared from $\mathrm{H}_{3} \mathrm{PW}_{12} \mathrm{O}_{40}$ and poly[( $\mathrm{N}$-isopropylacrylamide)-co-(acrylamide with ammonium salt)] is suitable for oxidation of alcohols, amines, and sulfides in aqueous hydrogen peroxide. PdAS 2

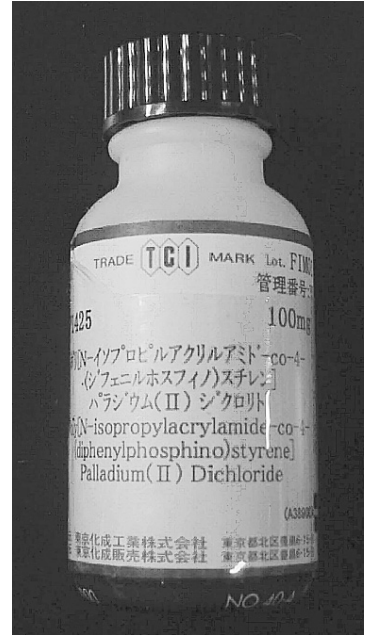

Fig. 6. Commercially Available PdAS from TCI

produced by self-organization of $\left(\mathrm{NH}_{4}\right)_{2} \mathrm{PdCl}_{4}$ and poly $[(\mathrm{N}$ isopropylacrylamide) $)_{10}$-co-diphenylphosphinostyrene] is an excellent recyclable catalyst for Suzuki-Miyaura reaction in water, water-organic solvent, and organic solvent, is commercially available from Tokyo Kasei Kogyo (TCI) (Fig. 6). PdAS-V 3 assembled from $\left(\mathrm{NH}_{4}\right)_{2} \mathrm{PdCl}_{4}$ and poly[ $(N$-isopropylacrylamide $)_{5}$-co-diphenylphosphinostyrene] provides recycling system of itself for Mizorogi-Heck reaction. TiSS 4 made from $\mathrm{Ti}(\mathrm{O}-i-\mathrm{Pr})_{4}$ and poly(styryl-linked binaphtholate-co-styrene) promotes an enantioselective carbonyl-ene reaction as a recyclable catalyst. I believe that this concept for the preparation of highly active and reusable catalysts apply not only for other catalytic systems but also for other supramolecular chemistry, so that I would like to expand this new world for 21 st century chemistry.

Acknowledgements The research presented here was performed at Faculty of Pharmaceutical Sciences, Teikyo University. I would like to express my deep gratitude to Prof. Shiro Ikegami for his kind and great help during the research and for his financial support. I am very thankful to Dr. Hideyo Takahashi for her suitable advice and kind help. I also thank Mr. Masato Ichinohe, Mr. Hidetsugu Tabata, and Mr. Koji Takeda for their good coworking. They worked very hard with me to develop the aforementioned projects. I also thank Ms. Junko Shimode, Ms. Maroka Kitsukawa, and Mr. Kiyoshi Abe for spectroscopic measurement. This work was partially supported by a Grant-in-Aid for Scientific Research from the Ministry of Education, Science and Technology. I also thank the Inoue Foundation for Science (IFS) for Inoue Research Award for Young Scientists, and Dainippon Ink and Chemicals, Inc. Award in Synthetic Organic Chemistry, Japan.

\section{References and Notes}

1) Anastas P. T., Warner J. C., "Green Chemistry: Theory and Practice," Oxford Univ. Press, Oxford, 1998.

2) Tundo P., Anastas P., Black D. S., Breen J., Collins T., Memoli S., Miyamoto J., Polyakoff M., Tumas W., Pure Appl. Chem., 72, 12071228 (2000).

3) de Miguel Y. R., J. Chem. Soc., Perkin Trans. 1, 2000, 4213-4221 (2000).

4) Shuttleworth S. J., Allin S. M., Wilson R. D., Nasturica D., Synthesis, 2000, 1035-1074 (2000).

5) Loch J. A., Crabtree R. H., Pure Appl. Chem., 73, 119-128 (2001).

6) Corain B., Kralik M., J. Mol. Catal A: Chem., 173, 99-115 (2001).

7) Bergbreiter D. E., Curr. Opin. in Drug Discovery \& Development, 4, $736-744$ (2001).

8) Cameron J. H., "Solid State Organometallic Chemistry Methods and Applications," ed. by Gielen M., Willem R., Wrackmeyer B., Wiley, Chichester, 1999.

9) Buchmeiser M. R., "Polymer Materials in Organic Synthesis and 
Catalysis," Wiley-VCH, Weinheim, 2003.

10) Centi G., Cavani F., Trifiro F., "Selective Oxidation by Heterogeneous Catalysis (Fundamental and Applied Catalysis)," Kluwer Academic Pubs, Norwell, MA, 2000.

11) Hodnett K., "Heterogeneous Catalytic Oxidation," Wiley, New York, 2000.

12) Bunin B. A., "The Combinatorial Index," Academic Press, San Diego, 1998

13) "Reactions on Polymers," ed. by Moore J. A., Redel, Boston, 1973.

14) "Solid Phase Synthesis," ed. by Blossey E. C., Neckers D. C., Dowden, Hutchinson and Ross, Pennsylvania, 1975.

15) Corma A., García H., Chem. Rev., 102, 3837-3892 (2002).

16) Yamada Y. M. A., Ichinohe M., Takahashi H., Ikegami S., Org. Lett., 3, 1837-1841 (2001).

17) Yamada Y. M. A., Ichinohe M., Takahashi H., Ikegami S., Tetrahedron Lett., 43, 3431-3434 (2002).

18) Yamada Y. M. A., Takeda K., Takahashi H., Ikegami S., Org. Lett., 4, $3371-3374$ (2002).

19) Yamada Y. M. A., Tabata H., Takahashi H., Ikegami S., Synlett, 2002, 2031-2034 (2002)

20) Yamada Y. M. A., Takeda K., Takahashi H., Ikegami S., Tetrahedron Lett., 44, 2379-2382 (2003).

21) Yamada Y. M. A., Takeda K., Takahashi H., Ikegami S., J. Org Chem., 68, 7733-7741 (2003).

22) Yamada Y. M. A., Tabata H., Ichinohe M., Takahashi H., Ikegami S., Tetrahedron, 60, 4087-4096 (2004).

23) Yamada Y. M. A., Takeda K., Takahashi H., Ikegami S., Tetrahedron, 60, 4097-4105 (2004).

24) Jacobs and co-workers reported the Amberlite IRA-900-supported Venturello catalyst converted into $\mathrm{NO}_{3}^{-}$was effective for the enhancement of selectivity of epoxidation, see: Villa A. L., Sels B. F., de Vos D. E., Jacobs P. A., J. Org. Chem., 64, 7267-7270 (1999).

25) Ishii Y., Yamawaki K., Ura T., Yamada H., Yoshida T., Ogawa M., $J$. Org. Chem., 53, 3587-3593 (1988).

26) Massart R., Contant R., Fruchart J.-M., Ciabrini J.-P., Fournier M., Inorg. Chem., 16, 2916-2921 (1977).

27) Ishii Y., Tanaka H., Nishiyama Y., Chem. Lett., 1994, 1 - 4 (1994).

28) Keggin J. F., Proc. R. Soc. London, Ser. A, 144, 75-100 (1934).

29) Brown G. M., Noe-Spirlet M.-R., Busing W. R., Levy H. A., Acta Cryst. B, 33, 1038-1046 (1977).

30) Ogata Y., Sawaki Y., "Organic Syntheses by Oxidation with Metal Compounds," ed. by Mijs W. J., De Jonge C. R. H. I., Plenum Press, New York, 1986, pp. 839-876.

31) Sato K., Aoki M., Noyori R., Science, 281, 1646-1647 (1998).

32) Venturello C., Gambaro M., J. Org. Chem., 56, 5924-5931 (1991).

33) Venturello C., Gambaro M., Synthesis, 1989, 295-297 (1989).

34) Bortolini O., Conte V., Di Furia F., Modena G., J. Org. Chem., 51, 2661-2663 (1986).

35) Villa A. L., Sels B. F., De Vos D. E., Jacobs P. A., J. Org. Chem., 64, 7267-7270 (1999).

36) Hoegaerts D., Sels B. F., de Vos D. E., Verpoort F., Jacobs P. A., Catal. Today, 60, 209-218 (2000).

37) Gelbard G., Breton F., Quenard M., Sherrington D. C., J. Mol. Catal. A: Chem., 153, 7-18 (2000).

38) Sakamoto T., Pac C., Tetrahedron Lett., 41, 10009-10012 (2000).

39) Briot E., Piquemal J.-Y., Vennat M., Brégeault J.-M., Chottard G., Manoli J.-M., J. Mater. Chem., 10, 953-958 (2000).

40) Ichihara J., Tetrahedron Lett., 42, 695-697 (2001).

41) De Bos D. E., Wahlen J., Sels B. F., Jacobs P. A., Synlett, 2002, 367380 (2002).

42) de Vos D. E., Jacobs P. A., J. Org. Chem., 64, 7267-7270 (1999).

43) It was reported that $\mathrm{pH}$ control in aqueous media was important for the tungsten-catalyzed epoxidation, see ref. 33, 34 and 36

44) Haines A. H., "Methods for the Oxidation of Organic Compounds," Academic Press, London, 1985.

45) Herrmann W. A., Fridgen J., Haider J. J., "Peroxide Chem.," ed. by Adam W., Wiley, Weinheim, 2000, pp. 406- 432.

46) Ogata Y., Tomizawa K., Maeda H., Bull. Chem. Soc. Jpn., 53, 285286 (1980).

47) Murahashi S., Mitsui H., Shiota T., Tsuda T., Watanabe S., J. Org. Chem., 55, 1736-1744 (1990).

48) Murahashi S., Oda T., Sugahara T., Masui Y., J. Org. Chem., 55, 1744-1749 (1990)

49) Sakaue S., Sakata Y., Ishii Y., Chem. Lett., 1992, 289-292 (1992).
50) Marcantoni E., Petrini M., Polimanti O., Tetrahedron Lett., 36, 3561-3562 (1995).

51) Ballistreri F. P., Barbuzzi E. G. M., Tomaselli G. A., J. Org. Chem., 61, 6381-6387 (1996).

52) Reddy J. S., Jacobs P. A., J. Chem. Soc. Perkin Trans. 1, 1993, 2665-2666 (1993)

53) Joseph R., Sudalai A., Ravindranathan T., Synlett, 11, 1177-1178 (1995).

54) Joseph R., Ravindranathan T., Sudalai A., Tetrahedron Lett., 36, 1903-1904 (1995).

55) Delaude L., Laszlo P., J. Org. Chem., 61, 6360-6370 (1996).

56) Dewkar G. K., Nikalje M. D., Ali I. S., Paraskar A. S., Jagtap H. S., Sudalai S., Angew. Chem. Int. Ed., 40, 405-408 (2001).

57) The reaction oxidized by more concentrated $\mathrm{H}_{2} \mathrm{O}_{2}$ aqueous solution was less successful because dimerization of the substrates occurred. Besides, recycling of PWAA in case of 11a was not efficient to afford 12a in lower yield.

58) These oxidations were controlled kinetically, and the regioselectivity for the formation of nitrones was determined at the oxidation stage of dibenzyl hydroxyamines to nitrones. It was assured by the following results: no isomerization between $\mathbf{1 2} \mathbf{e}$ and $\mathbf{e}^{\prime}$ was observed in the reaction of 12e or $\mathbf{e}^{\prime}$ in the presence of PWAA and $2.5 \% \mathrm{H}_{2} \mathrm{O}_{2}$, the reaction of 11e in $\mathrm{CH}_{2} \mathrm{Cl}_{2}$ at room temperature provided $12 \mathbf{e}$ and $\mathbf{e}^{\prime}$ in $95 \%$ yield with the same regioselectivity $\left(\mathbf{1 2} \mathbf{e} / \mathbf{1 2} \mathbf{e}^{\prime}=1.76 / 1\right)$, even in the reaction of $12 \mathbf{e}$ or $\mathbf{e}^{\prime}$ with $\mathrm{CH}_{2} \mathrm{Cl}_{2}$ under identical conditions, isomerizations were hardly observed.

59) Schultz H. S., Freyermuth H. B., Buc S. R., J. Org. Chem., 28 , $1140-1142$ (1963).

60) Stec Z., Zawadiak J., Skibinski A., Pastuch G., Polish J. Chem., 70, 1121-1123 (1996).

61) Neumann R., Juwiler D., Tetrahedron, 52, 8781-8788 (1996).

62) Gresley N. M., Griffith W. P., Laemmel A. C., Nogueira H. I. S., Perkin B. C., J. Mol. Catal., 117, 185-198 (1997).

63) Collins F. M., Lucy A. R., Sharp C., J. Mol. Catal., 117, 397-403 (1997).

64) Yasuhara Y., Yamaguchi S., Ichihara J., Nomoto T., Sasaki Y., Phosphorus Res. Bull., 11, 43-46 (2000).

65) Sato K., Hyodo M., Aoki M., Zheng X.-Q., Noyori R., Tetrahedron, 57, 2469-2476 (2001).

66) Dell'Anna M. M., Mastrorilli P., Nobile C. F., J. Mol. Catal. A: Chem., 108, 57-62 (1996).

67) Alcon M. J., Corma A., Iglesias M., Sanchez F., J. Mol. Catal. A: Chem., 178, 253-266 (2002).

68) Noyori et al. reported that the oxidation of sulfides to sulfoxides proceeded efficiently in hydrogen peroxide without catalysts, so that we have not examined the selective oxidation to sulfoxide. See ref. 65 .

69) Baudin J. B., Hareau G., Julia S. A., Ruel O., Tetrahedron Lett., 32, 1175-1178 (1991).

70) Kondo K., Tunemoto D., Tetrahedron Lett., 17, 1397-1400 (1975).

71) Caton M. P. L., Coffee E. C. J., Watkins G. L., Tetrahedron Lett., 9, $773-774$ (1972).

72) Brégault et al. reported that heteropoly acidic structure easily decomposed in the presence of hydrogen peroxide under the homogeneous conditions, see: Salles L., Aubry C., Thouvenot R., Robert F., Dorémieux-Morin C., Chottard G., Ledon H., Jeannin Y., Brégault J., Inorg. Chem., 33, 871-878 (1994). On the other hand, Ishii et al. proved that $\left[\pi-\mathrm{C}_{5} \mathrm{H}_{5} \mathrm{~N}^{+}\left(\mathrm{CH}_{2}\right)_{15} \mathrm{CH}_{3}\right]_{3} \mathrm{PW}_{12} \mathrm{O}_{40}^{3-}$ maintained the structure closed to Keggin unit after treatment with hydrogen peroxide. See ref. 27.

73) For an example of the Suzuki-Miyaura reaction used by homogeneous palladium catalysts prepared from poly $(N$-isopropylacrylamide) polymers as soluble and thermoresponsive catalysts: Bergbreiter D. E., Osburn P. L., Wilson A., Sink E. M., J. Am. Chem. Soc., 122, 9058-9064 (2000).

74) For an example of ( $\mathrm{N}$-isopropylacrylamide)polymer-protected palladium nanoparticles for hydrogenation, see: Chen C.-W., Akashi M., Polym., Adv. Technol., 10, 127-133 (1999).

75) Mann F. G., Purdie D., J. Chem. Soc., 1935, 1549-1563 (1935).

76) Miyaura N., Suzuki A., Chem. Rev., 95, 2457-2483 (1995).

77) Suzuki A., J. Organomet. Chem., 576, 147-168 (1999).

78) "Organometallics in Synthesis A Manual," ed. by Schlosser M., Miley, West Sussex, 2002.

79) Stanforth S. P., Tetrahedron, 54, 263-303 (1998).

80) Thompson L. A., Ellman J. A., Chem. Rev., 96, 555-600 (1996). 
81) Tsuji J., "Palladium Reagents and Catalysts: Innovations in Organic Synthesis," Wiley, Chichester, 1995.

82) Akiyama R., Kobayashi S., Angew. Chem. Int. Ed., 40, 3469-3471 (2001).

83) Cammidge A. N., Baines N. J., Bellingham R. K., Chem. Commun., 2001, 2588-2589 (2001).

84) LeBlond C. R., Andrew A. T., Sun Y., Sowa J. R., Jr., Org. Lett., 3, $1555-1557$ (2001).

85) Gordon R. S., Holmes A. B., Chem. Commun., 2002, 640-641 (2002).

86) Kim S.-W., Kim M., Lee W. Y., Hyeon T., J. Am. Chem. Soc., 124, $7642-7643$ (2002).

87) Uozumi Y., Nakai Y., Org. Lett., 4, 2997-3000 (2002).

88) Sakurai H., Tsukuda T., Hirao T., J. Org. Chem., 67, 2721-2722 (2002).

89) Mori K., Yamaguchi K., Hara T., Mizugaki T., Ebitani K., Kaneda K., J. Am. Chem. Soc., 124, 11572-11573 (2002).

90) Li C.-J., Chem. Rev., 93, 2023-2035 (1993),

91) Grieco P. A. (ed.), "Organic Synthesis in Water," Blackie Academic \& Professional, London, 1998.

92) Davies I. W., Matty L., Hughes D. L., J. Am. Chem. Soc., 123, $10139-10140$ (2001).

93) It was ascertained that thorough washing with water and THF in preparing PdAS was essential for removing a trace amount of active and homogeneous catalytic species from PdAS.

94) PdAS was reused after dried in vacuo.

95) These reactions afforded 300 to $400 \mathrm{mg}(2.25 \mathrm{mmol})$ of the products, so that it was difficult to isolate the products efficiently under organic solvent-free conditions.

96) Watanabe T., Miyaura N., Suzuki A., Synlett, 1992, 207-210 (1992)

97) For the synthesis of candesartan, see: Kubo K., Kohara Y., Imamiya E., Sugiura Y., Inada Y., Furukawa Y., Nishikawa K., Naka T., J. Med. Chem., 36, 2182-2195 (1993).

98) For the synthesis of losartan, see: Carini D. J., Duncia J. V., Aldrich P. E., Chiu A. T., Johnson A. L., Pierce M. E., Price W. A., Santella J. B., III, Wells G. J., Wexler R. R., Wong P. C., Yoo S.-E., Timmermans P. B. M. W. M., J. Med. Chem., 34, 2525-2547 (1991).

99) For the synthesis of L-158809, see: Mantlo N. B., Chakravarty P. K., Ondeyka D. L., Siegl P. K. S., Chang R. S., Lotti V. J., Faust K. A., Chen T.-B., Schorn T. W., Sweet C. S., Emmert S. E., Patchett A. A., Greenlee W. J., J. Med. Chem., 34, 2919-2922 (1991).

100) Organ M. G., Mayhew D. M., Cooper J. T., Dixon C. E., Lavorato D. J., Kaldor S. W, Siegel M. G., J. Comb. Chem., 3, 64-67 (2001).

101) Organ M. G., Arvanitis E. A., Dixon C. E., Cooper J. T., J. Am. Chem. Soc., 124, 1288-1294 (2002).

102) Ishiyama T., Miyaura N., Suzuki A., Org. Synth., 71, 89-96 (1993).

103) Ishiyama T., Abe S., Miyaura N., Suzuki A., Chem. Lett., 1992, 691-694 (1992).

104) Chemler S. R., Trauner D., Danishefsky S. J., Angew. Chem. Int. Ed., 40, $4544-4568$ (2001).

105) Maddaford S. P., Keay B. A., J. Org. Chem., 59, 6501-6503 (1994).

106) Chowdhury S., Georghiou P. E., Tetrahedron Lett., 40, 7599-7603 (1999).

107) Juteau H., Gareau Y., Labelle M., Lamontagne S., Tremblay N., Carriére M.-C., Sawyer N., Denis D., Metters K. M., Bioorg. Med. Chem. Lett., 11, 747-749 (2001).

108) Botella L., Nájera C., Angew. Chem. Int. Ed., 41, 179-181 (2002).

109) When the reaction of benzyl bromide with $20 \mathrm{~b}$ ( $1.5 \mathrm{moleq})$ with PdAS $\left(5 \times 10^{-4} \mathrm{~mol} \mathrm{eq}\right)$ and $\mathrm{KF}(3 \mathrm{~mol} \mathrm{eq})$ in $\mathrm{H}_{2} \mathrm{O}$ was performed for $24 \mathrm{~h}, 29 \mathrm{a}$ was obtained in $65 \%$ yield with a significant amount of anisole that was produced by hydrolysis of $\mathbf{2 0 b}$.

110) Beletskaya I. P., Cheprakov A. V., Chem. Rev., 100, 3009-3066 (2000).

111) Whitcombe N. J., Hii K. K. (M.), Gibson S. E., Tetrahedron, 57, 7449-7476 (2001).

112) Biffis A., Zecca M., Basato M., J. Mol. Catal. A: Chem., 173, 249274 (2001).

113) Uozumi Y., Hayashi T., "Handbook of Combinatorial Chemistry," ed. by Nicolaou K. C., Hanko R., Hartwig W., Wiley, Weinheim, 2002.

114) Zhou J., Zhou R., Mo L., Zhao S., Zheng X., J. Mol. Catal. A: Chem., 178, 289-292 (2002).

115) Gordon R. S., Holmes A. B., Chem. Commun., 2002, 640-641 (2002).

116) Dams M., Drijkoningen L., De Vos D., Jacobs P., Chem. Commun., 2002, 1062-1063 (2002).

117) Galow T. H., Drechsler U., Hanson J. A., Rotello V. M., Chem. Commun., 2002, 1076-1077 (2002).

118) Heidenreich R. G., Köhler K., Krauter J. G. E., Pietsch J., Synlett, 2002, 1118-1122 (2002).

119) Chandrasekhar V., Athimoolam A., Org. Lett., 4, 2113-2116 (2002).

120) Dell'Anna M. M., Mastrorilli P., Muscio F., Nobile C. F., Suranna G. P., Eur. J. Org. Chem., 2002, $1094-1099$ (2002).

121) Mori K., Yamaguchi K., Hara T., Mizugaki T., Ebitani K., Kaneda K., J. Am. Chem. Soc., 124, 11572-11573 (2002).

122) The homogeneous Heck reaction catalyzed by poly $(N$-isopropylacrylamide)-palladium complex under soluble and thermomorphic conditions, see: Bergbreiter D. E., Osburn P. L., Wilson A., Sink E. M., J. Am. Chem. Soc., 122, 9058-9064 (2000).

123) Buchmeiser M. R., Lubbad S., Mayr M., Wurst K., Inorg. Chim. Acta, 345 145-153 (2002).

124) Uozumi Y., Kimura T., Synlett, 2002, 2045-2048 (2002).

125) Kogan V., Aizenshtat Z., Popovitz-Biro R., Neumann R., Org. Lett., 4, 3529-3532 (2002).

126) Mukhopadhyay S., Rothenberg G., Joshi A., Baidossi M., Sasson Y., Adv. Synth. Cat., 344, 348-354 (2002).

127) Jang M., Cai L., Udeani G. O., Slowing K. V., Thomas C. F., Beecher C. W. W., Fong H. H. S., Farnsworth N. R., Kinghorn A. D., Mehta R. G., Moon R. C., Pezzuto J. M., Science, 275, 218-220 (1997).

128) Subbaramaiah K., Dannenberg A. J., Adv. Experi. Med. Biol., 492, 147-157 (2001).

129) Ciolino H. P., Yeh G. C., Adv. Experi. Med. Biol., 492, 183-193 (2001).

130) Sovak M., J. Med. Food, 4, 93-105 (2001).

131) Orsini F., Pelizzoni F., Bellini B., Miglierini G., Carbohydr. Res., 301, 95-109 (1997)

132) Recently, Gruiso reported syntheses of resveratrol via the homogeneous Heck reaction (70\% yield) using $\mathrm{Pd}(\mathrm{OAc})_{2}$ and $\mathrm{PPh}_{3}$, used in $1 \times 10^{-2} \mathrm{~mol} \mathrm{eq}$, see: Guiso M., Marra C., Farina A., Tetrahedron Lett., 43, 597-598 (2002).

133) Reek J. N. H., Priem A. H., Engelkamp H., Rowan A. E., Elemans J. A. A. W., Nolte R. J. M., J. Am. Chem. Soc., 119, 9956-9964 (1997).

134) Lipshutz B. H., Shin Y.-J., Tetrahedron Lett., 41, 9515-9521 (2000).

135) Yang X.-W., Sheng J.-H., Da C.-S., Wang H.-S., Su W, Wang R., Chan A. S. C., J. Org. Chem., 65, 295-296 (2000).

136) Sellner H., Faber C., Rheiner P. B., Seebach D., Chem. Eur. J., 6, $3692-3705$ (2000).

137) Jayaprakash D., Sasai H., Tetrahedron: Asymmetry, 12, 2589-2595 (2001).

138) Kitamoto D., Imma H., Nakai T., Tetrahedron Lett., 36, 1861-1864 (1995).

139) Terada M., Mikami K., J. Chem. Soc. Chem. Commun., 1994, 833834 (1994).

140) Annunziata R., Benaglia M., Cinquini M., Cozzi F., Pitillo M., J. Org. Chem., 66, 3160-3166 (2001).

141) This result would indicate that the self-assembly of 39 and $\mathrm{Ti}(\mathrm{O}-i$ $\mathrm{Pr})_{4}$ was not successful.

142) It is unclear why the reaction in THF did not proceed. The strong Lewis basicity of THF would reduce a Lewis acidity of the titanium catalyst.

143) The preparation of the catalyst was reproducible. A different batch of the catalyst was independently prepared from a different batch of the polymer, and showed identical activity and enantioselectivity in this reaction.

144) Cavorot M., Byrne J. J., Chavant P. Y., Pardillos-Guindet J., Vallée Y., Tetrahedron: Asymmetry, 9, 3889-3894 (1998). 